\title{
Trends and Spatial Variation of Female Genital Mutilation among Reproductive Age Women in Ethiopia based on 2000, 2005, and 2016 Ethiopian Demographic and Health Surveys: Spatial-temporal and Multivariate Decomposition Analysis
}

Getayeneh Antehunegn Tesema ( $\sim$ getayenehantehunegn@gmail.com )

University of Gondar College of Medicine and Health Sciences

Achamyeleh Birhanu Teshale

University of Gondar College of Medicine and Health Sciences

Chilot Desta Agegnehu

University of Gondar College of Medicine and Health Sciences

Adugnaw Zeleke Alem

University of Gondar College of Medicine and Health Sciences

Alemneh Mekuriaw Liyew

University of Gondar College of Medicine and Health Sciences

Yigizie Yeshaw

University of Gondar College of Medicine and Health Sciences

Sewnet Adem Kebede

University of Gondar College of Medicine and Health Sciences

Research article

Keywords: Ethiopia: FGM practice: Multivariate decomposition analysis: spatial analysis

Posted Date: October 26th, 2019

DOI: https://doi.org/10.21203/rs.2.16478/v1

License: (c) (i) This work is licensed under a Creative Commons Attribution 4.0 International License.

Read Full License 


\section{Abstract}

Introduction: Even if FGM has been declined dramatically in the world, the rate of decline is far below the rate needed to achieve SDG in Ethiopia. FGM remains as a serious public health concern in Ethiopia and the prevalence has varied across and within countries. Therefore, this study aimed to assess the trends and geographic variation of FGM practice in Ethiopia based on EDHSs. Methods: The study used the data from the three DHSs conducted in Ethiopia. Trend and Logistic based decomposition analysis technique was used for analyzing the change in FGM practice overtime and factors contributing to the change in FGM practice. STATA 14 was used for data management and analysis. The Bernoulli model was fitted using spatial scan statistics version 9.6 to identify hotspot areas and ArcGIS version 10.6 to explore the spatial distribution FGM. Results : The prevalence of FGM practice was decreased from $79.9 \%$ in 2000 to $70.4 \%$ in 2016 . The decomposition analysis indicated that about $95 \%$ of the overall decrease in FGM practice was due to the difference in the change in the behavior of FGM practice among urban residents, orthodox and Muslim followers, self-employed, education, and media exposure were significant factors contributed to the change in FGM over the study period. The SaTScan analysis identified 141 most likely clusters (LLR=711.9, $p<0.001)$ in 2000, 175 (LLR=576.4, $p<0.001)$ in 2005, and 220 (LLR= 243.6, $p<0.001)$ in 2016 which was located in Somali, Somali, Harari, and border areas of Somali consistently over the three surveys. Conclusions: These results showed that FGM practice has been declined in Ethiopia. The decrease in FGM practice could be attributable to the difference in the change in effects of residence, media exposure; religion, region, and educational status. The spatial analysis provides further insight into differences in FGM practice within the country and highlights primary and secondary clusters. This could enable efficient and timely spatial targeting of hotspot areas of FGM practice to achieve the goals of eliminating FGM practice in Ethiopia by 2025 and the government should scale up the public health programs to improve the rate of reduction.

\section{Background}

According to World Health Organization (WHO), Female Genital Mutilation (FGM) is defined as partial or total removal of the external female genitalia or other injuries to the female genital organs for nonmedical reasons that have no health benefits for girls and women (1). FGM is widely practiced in Africa, Asia, Middle East and some countries in South America and it has strong cultural beliefs that are linked to women's sexuality and their reproductive role in the society and is recognized internationally as a violation of the human rights of girls and women (2). Globally, more than 200 million girls and women undergo female genital mutilation, of these 125 million were occurred in Africa (3). Despite efforts to eradicate the FGM practice, an estimated 3 million girls are at risk of undergoing female genital mutilation every year and exposed to the health consequences of FGM and the parents allow their daughters to conform to the social tradition (4).

Female genital mutilation remains a major public health problem worldwide $(2,5)$. It is highly practiced in Africa, mostly in the north-eastern region of Africa: Djibouti, Eritrea, Ethiopia, and Somalia (6). The trend of girls undergoing female genital mutilation has reduced dramatically in Africa. According to the 
systematic analysis based on DHS data from 29 African countries and 2 west Asian countries, the prevalence of female genital mutilation has varied greatly between countries and regions and also varied within countries over time. The rates of FGM have been decreased in North Africa from $57.7 \%$ in 1990 to $14.1 \%$ in 2015. In West Africa, the trends of FGM have decreased from $73.6 \%$ in 1996 to $25.4 \%$ in 2017. Whereas, the trends of FGM in East Africa has been reduced from $71.4 \%$ in 1995 to 8\% in 2016 (7). Countries with the highest prevalence of FGM among women aged 15 to 49 are Somalia at 98 percent, Guinea at 97 percent, Djibouti 93 percent and Egypt at 87 percent (8).

Eliminating FGM is the focus of governments and NGOs all over the world. The Ethiopian government has prioritized sustainable development goal 5.3 as one of the national development targets and it outlined strategic measures to reduce FGM practice that can contribute to the elimination of FGM in Ethiopia $(9,10)$. In Ethiopia, FGM has been decreased from 79.9 in 2000 to $65 \%$ in 2016 (11-13). Despite this progress, FGM remains a serious public health problem in Ethiopia and has affected 23.8 million women and girls, making Ethiopia the second-highest FGM practice in Africa (14). Despite a significant reduction in FGM nationally over the past decades, the UNICEF report from the 2011 Welfare and Monitoring Survey one in every four girls are subjected to the practice and the risk varies across regions with the highest prevalence in Somali and Afar regions (15).

FGM has serious physical and psychological consequences to women, risking their lives at the time of circumcision, at marriage, during birth and decrease their attendance and performance in schools (16). The practice has been associated with significant health consequences such as complications during pregnancy and childbirth, menstrual abnormality, post-traumatic stress disorder, recurrent pelvic and vaginal infection (17).

Although there are studies conducted on the prevalence of female genital mutilation in different parts of Ethiopia (18-24) and one study done on Geographic variation of FGM based on nationally representative EDHS data (21) and the result of these studies showed that there is geographic variability of the prevalence of FGM practice within the country but this study only explore the spatial distribution of prevalence of FGM in Ethiopia, they did not conducted Spatial autocorrelation, Hotspot analysis, interpolation, SaTScan analysis and trend analysis since this is important to identify significant hotspot areas and change in FGM practice across areas which is important for designing effective public health interventions and to identify the factors contributing for the decline in FGM practice over time in Ethiopia which is important to evaluate already implemented policies and programmers and to work on it.

Even if the prevalence of FGM has been decreased overtime in Ethiopia (11-13), still there are areas with a high prevalence of FGM in different parts of the countries. Therefore having information on the trend of FGM among women is necessary for the development of public health policies for the prevention of FGM practice in the identified hotspot areas of FGM, and would help policymakers to work on factors contributing to the change in FGM overtime and design public health interventions. The ultimate aim of this study is to inform decision and policymakers to design effective public intervention across geographic regions. To fill this research gap, we therefore used the three consecutive Ethiopian 
Demographic and Health Survey (EDHS) 2000, 2005 and 2016 data sets to assess the trends and spatial variation of FGM in Ethiopia using a multivariate decomposition and spatial analysis to identify the determinants factors contributing for the decline in FGM from 2000 to 2016. Thus, the government gives more attention to the most significant contributing factors and design and implement appropriate interventions for further decline of FGM in Ethiopia. Understanding the trends and geographic variations of FGM also would help public health planners, policymakers, programmers, and partners to design effective strategies and interventions to reduce FGM practice in Ethiopia.

\section{Methods}

Study design and Study settings

Repeated cross-sectional study design was employed using Ethiopian Demographic and Health surveys (EDHSs) in 2000, 2005, and 2016 to explore the trend and spatial variation of FGM. Since EDHS 2011 FGM data was not collected, EDHS 2011 was not used for this study. Ethiopia is located in the horn of Africa and it has been divided into nine regions and two city administrations (Figure 1). Ethiopia is an agrarian country and agriculture accounts for 43 percent of the gross domestic product (GDP) and $84 \%$ of the population lives in rural areas. More than 80 percent of the country's total population lives in the regional states of Amhara, Oromia, and SNNPRs (25). In 2016, the population was 102 million of which $43.47 \%$ the population ages less than 14 years with birth rate of 36.5 births per 1000 population and fertility rate of 4.46, Ethiopia is the13th in the world and 2nd in Africa most populous country Ethiopia has 3 tiers health systems, Primary health care unit (Primary hospital, health center, health post, primary clinic, and medium clinic); Secondary health care (General hospital, specialty clinics and specialty centers); and Tertiary health care (Specialized hospital). The number of hospitals varies from region to region in response to differences in population size. The most populous region, Oromia has 30 hospitals. The other two predominant regions Amhara and SNNPR have 19 and 20 respectively with Tigray in fourth place with 16 hospitals, Gambela has only one hospital and Benishangul-Gumuz two had two hospitals (26).

Sample and Source population

The source population was all reproductive-age women within five years before the survey in Ethiopia and all reproductive-age women in the selected enumeration areas within five years before the survey were the study population. The EDHS used a stratified two-stage cluster sampling technique selected in two stages using the 1994 population and housing census frame for EDHS 2000 and 2005, and the 2007 Population and Housing Census frame for EDHS 2016 as a sampling frame. Stratification was achieved by separating each region into urban and rural areas. In total, 21 sampling strata have been created because the Addis Ababa region is entirely urban. In the first stage, 539 Enumeration Areas (EAs) (138 
EAs in urban) for EDHS 2000, 540 EAs (145 in urban area) for EDHS 2005, and 645 EAs (202 in urban area) for EDHS 2016 were selected with probability proportional to the EA size and with independent selection in each sampling stratum. At the second stage, because the time has passed since the $\mathrm{PHC}, \mathrm{a}$ complete household listing operation was carried out in all selected EAs before the start of fieldwork and on average 27 to 32 households were systematically selected. A total weighted sample of 15,367 in EDHS 2000, 14,070 in EDHS 2005 and 7,248 reproductive-age women were used for analysis. The detailed sampling procedure was presented in the full EDHS report $(11,12$, and 27$)$.

Study variables

\section{Outcome variables}

The EDHS asked women to answer to the question "having experiencing Female genital mutilation?". The response variable of this study was whether circumcised or not. The response variable for the ith mother is represented by a random variable Yi with two possible values coded as "yes" and "No". So, the response variable of the ith mother $Y i$ was measured as a dichotomous variable with possible values $Y i=Y e s$ if ith mother had experienced circumcision and $\mathrm{Yi}=$ No if mother did not experience circumcision.

Independent variables

Independent factors that were considered to affect the practice of female genital mutilation like the place of residence, religion, geographic region, age of women, maternal education, women occupation, media exposure and wealth status were included for the study.

Data collection procedure

The study was conducted based on EDHS data by accessing from the DHS program official database (www.measuredhs.com) after permission was granted through an online request by explaining the objective of our study. The raw data was collected from all parts of the country on childbearing aged women using a structured and pre-tested questionnaire (11-13). We used the women data set and extracted the outcome and independent variables. Geographic coordinate data (longitude and latitude coordinates) was taken at the cluster level/ enumeration area level.

Data management and analysis 
Before the actual data collection, the Pre-test was conducted which consisted of in-class training, biomarker training, and field practice days. The questionnaires were pretested in all three local languages (Amharic, Oromia, and Tigrigna) to make sure that the questions were clear and could be understood by the respondents. The data were weighted using sampling weight, primary sampling unit, and strata before any statistical analysis to restore the representativeness of the survey and to tell the STATA to take into account the sampling design when calculating standard errors to get reliable statistical estimates. Cross tabulations and summary statistics were conducted to describe the study population. Descriptive and summary statistics were done using STATA version 14 software. Data from EDHS 2000, 2005 and 2016 were appended together after extracting important variables for trend and decomposition analysis.

Trend and Decomposition analysis

The trend was assessed using descriptive analyses stratified by selected respondent characteristics and was assessed separately for the periods 2000-2005, 2005-2016, and 2000-2016. Logit based decomposition analysis technique was used for the analysis of factors contributing to the change in FGM over the period to identify the sources of changes in stillbirth rate in the last 16 years.

The changes of FGM over time can be attributed to compositional changes between surveys and changes in the effects of the selected explanatory. Hence, the observed difference in FGM between surveys is additively decomposed into a characteristics (or endowments) component and a coefficient (or effects of characteristics) component.

For logistic regression, the Logit or log-odd of FGM is taken as:

$\operatorname{Logit}(A)-\operatorname{Logit}(B)=F(X A \beta A)-F(X B B B)$

$\equiv[\underline{F}(\underline{X A} \underline{\beta A})-F(\underline{X B} \underline{\beta A})]+[\underline{F}(\underline{X B} \underline{\beta A})-F(\underline{X B} \underline{B}]$

E C

The E component refers to the part of the differential owing to differences in endowments or characteristics. The $\mathrm{C}$ component refers to that part of the differential attributable to differences in coefficients or effects.

The equation can be presented as:

$\operatorname{Logit}(A)-\operatorname{Logit}(B)=[\beta 0 A-\beta 0 B]+\Sigma X i j B *[\beta i j A-\beta i j B]+\Sigma \beta i j B *[X i j A-X i j B]$

- $X i j \mathrm{~B}$ is the proportion of the jth category of the ith determinant in the DHS 2000,

- XijA is the proportion of the jth category of the ith determinant in DHS 2016,

- BijB is the coefficient of the jth category of the ith determinant in DHS 2000, 
- BijA is the coefficient of the jth category of the ith determinant in DHS 2016,

- $B O B$ is the intercept in the regression equation fitted to DHS 2000, and

- BOA is the intercept in the regression equation fitted to DHS 2016.

The recently developed multivariate decomposition for the non-linear model was used for the decomposition analysis of stillbirth using mvdcmp STATA command (28).

Spatial analysis

For the spatial analysis ArcGIS version 10.6 software and SaTScan version 9.6 software.

Spatial autocorrelation analysis

The spatial autocorrelation (Global Moran's I) statistic measures whether FGM patterns were dispersed, clustered or randomly distributed in the study area (29). Moran's I is a spatial statistics used to measure spatial autocorrelation by taking the entire data set and produce a single output value which ranges from -1 to +1 . Moran's I Values close to -1 indicate FGM dispersed, whereas Moran's I close to +1 indicate FGM clustered and disease distributed randomly if I value is zero. A statistically significant Moran's I $(p<0.05)$ leads to rejection of the null hypothesis (FGM is randomly distributed) and indicates the presence of spatial autocorrelation.

Hot spot analysis (Getis-OrdGi statistic)

Getis-OrdGi* statistics were computed to measure how spatial autocorrelation varies over the study location by calculating $\mathrm{Gl}^{\star}$ statistic for each area. Z-score is computed to determine the statistical significance of clustering, and the $\mathrm{p}$-value computed for the significance. Statistical output with high $\mathrm{Gl}^{\star}$ indicates "hotspot" whereas low Gl* means a "cold spot"(30).

Spatial interpolation

It is very expensive and laborious to collect reliable data in all areas of the country to know the burden of a certain event. Therefore, part of a certain area can be predicted by using observed data using a method called interpolation. The spatial interpolation technique is used to predict stillbirth on the un-sampled areas in the country based on sampled EAs. There are various deterministic and geostatistical interpolation methods. Among all of the methods, ordinary Kriging and empirical Bayesian Kriging are considered the best method since it incorporates the spatial autocorrelation and it statistically optimizes 
the weight (31). Ordinary Kriging spatial interpolation method was used for this study for predictions of FGM in unobserved areas of Ethiopia.

Spatial scan statistical analysis

Spatial scan statistical analysis Bernoulli based model was employed to test for the presence of statistically significant spatial clusters of FGM using Kuldorff's SaTScan version 9.6 software. The spatial scan statistic uses a circular scanning window that moves across the study area. Women are circumcised were taken as cases and women who are not circumcised were taken as controls to fit the Bernoulli model. The numbers of cases in each location had Bernoulli distribution and the model required data for cases, controls, and geographic coordinates. The default maximum spatial cluster size of $<50 \%$ of the population was used, as an upper limit, which allowed both small and large clusters to be detected and ignored clusters that contained more than the maximum limit.

For each potential cluster, a likelihood ratio test statistic and the p-value were used to determine if the number of observed FGM cases within the potential cluster was significantly higher than expected or not. The scanning window with maximum likelihood was the most likely performing cluster, and the p-value was assigned to each cluster using Monte Carlo hypothesis testing by comparing the rank of the maximum likelihood from the real data with the maximum likelihood from the random datasets. The primary and secondary clusters were identified and assigned p-values and ranked based on their likelihood ratio test, based on 999 Monte Carlo replications (32).

Ethical approval and consent to participate

The study was based on secondary analysis of existing survey data with all identifying information removed. Permission for data access was obtained from measure demographic and health survey through an online request from http://www.measuredhsprogram.com. Prior to the actual interview, each woman was asked if she agreed to participate in the study. The GIS data were obtained through explaining the purpose of using GPS data and approval from Measure DHS. Informed consent was obtained from the participants, their guardian or household heads.

\section{Results}

Characteristics of respondents

About one-third of the respondents in all three surveys were found in the Oromia region. Based on the place of residence, there was a slight increment of respondents residing in urban areas from $18.2 \%$ in 2000 to $23.0 \%$ in 2016. According to maternal educational status, in survey 2000 more than three quarters $(75.2 \%)$ of women's were not educated, while it was decreased to $65.9 \%$ and $47.0 \%$ in EDHS 
2005 and 2016 respectively and the proportion of women with higher education has been increased from $0.5 \%$ in 2000 to $6.2 \%$ in 2016 . Besides the proportion of women who had media exposure has been increased from $34 \%$ in 2000 to $43.3 \%$ in 2016 . Except for religion, maternal age, region and wealth index, all other variables listed in the table showed changes in the composition of women, when comparing the sample population in the years 2000, 2005 and 2016 (Table 1).

Trends of female genital mutilation from EDHS 2000 to 2016 in Ethiopia

Figure 2 presents the trends in female genital mutilation among reproductive-age women during the period 2000-2016. With regard to the overall trends of FGM, Ethiopia has shown a significant decline in female genital mutilation over the study period, from $79.9 \%(95 \% \mathrm{Cl}: 79.3,80.5)$ in 2000 to $74.3 \%$ (95\% Cl: $73.5,74.9)$ in 2005 to $70.4 \%$ (95\% Cl: 69.3, 71.4) in 2016.

Trends in female genital mutilation among reproductive-age women by selected characteristics 2000 , 2005, and 2016 Ethiopian Demographic and Health Surveys

The trend period was divided into three phases, 2000-2005, 2005-2016, and 2000-2016, to see the difference in decreases in FGM overtime. The rate of female genital mutilation practice has been decreased over time. The largest decline was seen in the third phase of the study period (2000-2016) with a 9.5 percentage point change in FGM compared with 5.6 percentage point change in the first phase (2000-2005) and 3.9 percentage point change in FGM in the second phase (2000-2016).

The trends in female genital mutilation among women showed variation with respect to their characteristics. Major decreases in FGM were observed in some of the selected variables.

Four regions such as Tigray, Harari, Addis Ababa, and Dire-Dawa showed the greatest decline in FGM practice between 2000 and 2016 but the prevalence of FGM in the Somali region remains high (Figure 3).

Among urban residents, the largest decline in FGM practice has been observed during the third phase of the study period (2000-2016), at 24.3 percentage point decrease as compared with 11.3 percentage point decrease during the first phase (2000-2005) and a 13.0 percentage point decrease during the second phase (2005-2016). Young age women (15-19 years) showed a larger decrease in FGM by 19.1 percentage point change during the overall study period (2000-2016). Reproductive age women with secondary and higher education showed a 34.8 percentage point decrease during the third phase of the study period (2000-2016) (Table 2).

Decomposition analysis 
The decomposition analysis revealed that about $95 \%$ of the overall percentage change in FGM practice among reproductive-age women in Ethiopia was due to difference in coefficient (effects of characteristics) and the remaining $5 \%$ was due to the difference in characteristics (compositional factors or endowment) but the difference was not significant (Table 3). After controlling for the roles of compositional changes, a significant decrease in FGM practice was associated with the change in effects of residence, region, educational status, religion, occupation, and media exposure. About $20 \%$ of the decrease in FGM practice over the last 16 years was attributable to the change in effect among the urban population. As compared to the Somali region, the change in the effect of FGM practice among the Tigray population contributes about $12.2 \%$ of the overall decrease in FGM over the study period. Other factors such as a decrease in the effects of higher education women, Muslim and orthodox religious followers, media exposure were significantly contributed to the change in FGM practice in Ethiopia for the last 16 years (Table 4).

Spatial distribution of FGM practice

Spatial variation of FGM practice was found across regions and was non-random (Figure 4). Of the interviewed 15,367 in EDHS 2000 women, 12,280 (79.9\%) women were circumcised, of 14,070 interviewed women in EDHS 2005, 10,448 (74.3\%) women were circumcised and of 7,248 women interviewed women in EDHS 2016, 5,103 (70.4\%) women were circumcised. The highest FGM practice was spatially clustered in Somali, Harari, east Benishangul Gumuz, Amhara, Oromia, east SNNPRs and southern Afar regions consistently overtime, while Gambella, Tigray, northeast Amhara, west SNNPRs and northeast Benishangul Gumuz regions showed the lowest FGM practice (Figure 5).

The spatial pattern of FGM practice

Based on EDHS 2000, 2005 and 2016 sampled data, the hotspot analysis using Getis Ord Gi statistics revealed that significant hot spot areas were located in southeast Amhara, south Afar, East SNNPRs, Harari, Dire Dawa, and northeast Somali regions in EDHS 2000, whereas in EDHS 2005 hotspot areas were located in east Amhara, south Afar, northeast Somali, Dire Dawa, Harari, Central Oromia and east SNNPRs and in 2016 the hotspot areas consistently located in eastern border areas of Amhara, Benishangul Gumuz, east SNNPRs, Harari, Diredawa, Afar, and Somali region (Figure 6). In EDHS 2000, spatial scan statistics identified 427 significant primary and secondary clusters. Of these, 141 clusters were the most likely clusters (primary clusters) and the spatial window was located in north Somali, Harari, Dire Dawa, south Afar, and southeast Amhara region centered at $9.867651 \mathrm{~N}, 43.086403 \mathrm{E}$ with $348.25 \mathrm{~km}$ radius, a Relative Risk (RR) of 1.35, and Log-Likelihood Ratio (LRR) of 711.9, at p-value $<0.001$. It showed that women within the spatial window had 1.35 times higher risk for being circumcised as compared to women outside the spatial window (Table 5), whereas the secondary clusters were located in Amhara, Tigray, Benishangul Gumuz, SNNPRs, and Oromia regions (Figure 7). 
In EDHS 2005, a spatial scan statistics identified a total of 468 significant primary and secondary clusters. Of these, 175 clusters were the most likely clusters (primary clusters) and the spatial window was located in the entire Somali region and border areas of Somali regions, centered at $9.774395 \mathrm{~N}$, 43.208576 E with a radius of $484.13 \mathrm{~km}$, a Relative Risk (RR) of 1.42, and Log-likelihood (LLR=576.4, pvalue $<0.0001$ ) (Table 6). It showed that women within the spatial window had 1.42 times higher risk of being circumcised as compared to women outside the spatial window and the secondary clusters were located in Benishangul, Amhara, Oromia, and Gambella regions (Figure 7).

In EDHS 2016, a spatial scan statistics identified a total of 581 significant primary and secondary clusters. Of these, 220 clusters were the most likely clusters (primary clusters) and the spatial window was located in the entire Somali, Afar and border areas of Somali, centered at $7.717178 \mathrm{~N}, 46.991580 \mathrm{E}$ with a radius of $900.49 \mathrm{~km}$, a Relative Risk (RR) of 1.42, and Log-likelihood (LLR=243.6, p-value<0.0001) (Table 7). It showed that women within the spatial window had 1.42 times higher risk of circumcision as compared to women outside the spatial window (Figure 7).

Kriging interpolation of FGM practice

Based on EDHS 2000 sampled data, Kriging interpolation predict that the highest FGM practice was detected in the entire Somali, Oromia, Harari, Dire Dawa, Addis Ababa, Benishangul Gumuz, southeast Afar, southeast Amhara, and east SNNPRs. In contrast, relatively low FGM practice areas were predicted in the entire Tigray, Gambella, southwest Oromia, north Benishangul, northwest Amhara and north Afar (Figure 8). Based on EDHS 2005, Kriging interpolation predict that the highest FGM practice was detected in east SNNPRs, most of Oromia, west Benishangul, some parts of Oromia, southeast Amhara, and most of Afar regions. In contrast, predicted low FGM practices were detected in Tigray, northwest Gambella, north Afar, and west SNNPRs (Figure 8). From EDHS 2016 data, Kriging interpolation predicted that most parts of Oromia, entire Somali, Dire Dawa, Harari, Afar, and west Benishangul contained the highest FGM practice while most parts of Amhara, Tigray, Gambella and West SNNPRs contained relatively low FGM practice (Figure 8)

\section{Discussion}

Even if the United Nations Sustainable Development Goals (SDGs) and Ethiopia efforts to eliminate female genital mutilation by criminalizing the practice, still FGM practice remains a major public health concern in Africa including Ethiopia. The trend in FGM practice has been significantly declined in Ethiopia. It is in line with studies done in Ghana (33), Oromia (34), Nigeria (35), Burkina Faso (36) and Gambia (37). This could be due to systematic efforts of government and non-governmental organizations for the elimination of FGM by engaging the community to accelerate the abandonment of the practice of FGM, engaging programmers to work with the communities, increase health education and health promotion to the communities (38). 
The rate of FGM practice in Ethiopia has been declined from $79.9 \%$ in 2000 to $70.4 \%$ in 2016 with the annual rate of reduction of $0.9 \%$. Even though the prevalence of FGM has been dropped, the rate of decline is far below to achieve the sustainable development goal 5 . which is slower than systematic study in, east Africa which was reduced from $71 \%$ to $8 \%$ within 20 years with annual rate of reduction of $3.2 \%$, west Africa which was reduced from $73.6 \%$ to $25.4 \%$ within 21 years with annual rate of reduction of $2.3 \%$ and North Africa from $57.7 \%$ to $14.1 \%$ within 23 years with annual rate of reduction of $1.9 \%$ (38). This could be due to that FGM practice in Ethiopia is deeply rooted in traditions and persisted as a social norm for a long period and lack of resource allocation to provide health education to the communities (39). Therefore much progress is needed to achieve the SDG goals.

The multivariate decomposition analysis identified the determinants contributing to the change in FGM practice over the last 16 years. Hence, understanding the factors contributing to the decline in FGM practice in Ethiopia has public health importance. The decomposition analysis revealed that about $95 \%$ of the decrease in FGM practice in Ethiopia over the past 16 years is due to the difference in effects of characteristics (coefficient) but the change due to the difference in endowment (composition) was not significant. One of the findings was, about $20.6 \%$ of the decrease in FGM practice in Ethiopia was due to the change in FGM practice among the urban population. This is in line with a study done in Egypt (40), this might be due to improvement better access of information and education over time and this could favor urban residents, and aware of the negative health consequences of FGM relative to rural residents and this could contribute for the decrease in FGM (41).

Also, the change in the effect of Muslim and orthodox religious followers contributes to the change in FGM practice over time, it is supported by the previous study (42) and this showed the behavior of religious followers towards FGM practice has been improved. The change could be due to the engagement of faith leaders by the government to improve awareness of the community towards the consequence of FGM in Ethiopia (38). The other contributing factors for the change in FGM practice over the last 16 years were due to the change in the effect of women's occupation, women, education, Tigray residents, and media exposure. This could be due to the improvement in media exposure; job opportunity and access to education significantly contribute to women empowerment and their capacity to fight against harmful traditional practices such as FGM and child marriage. Therefore, women's education, media exposure and creating job opportunities were significantly contributing to the decline in FGM practice.

GIS-based spatial and SaTScan analysis showed that FGM practice was non-random. This was supported by a spatial study done in Nigeria (43), and Kenya (44). The hotspot and SaTScan analysis identified significant hotspot areas across the three EDHS surveys which were consistently located in the entire Somali, Afar, Harari and border areas of Somali regions. Even though there is a coordinated effort by engaging faith and community organizations to accelerate the abandonment of FGM practice in Ethiopia, Afar, and Harari and Somali regions were significant hot spot areas of FGM practice. This could be due to deeply rooted strong belief, attitudes and behaviors towards FGM practice in these regions and the belief that if a girl not get circumcised, the daughter may not get married and this makes the 
community female circumcision to get social acceptance(45). There is also evidence that hence FGM is deeply rooted in their tradition, there is resistance to abandoning FGM practice in Somali and afar region. This implies that the government needs to strengthen efforts to reduce the FGM practice in these regions by highly engaging the community leaders, civil society, school, media, faith leaders and females.

\section{Strengths And Limitations}

This study had several strengths. First, the study was based on nationally representative large datasets, and thus it had adequate statistical power. Second, the estimates of the study were done after the data were weighted for the probability sampling and non-response, to make it representativeness at national and regional levels: therefore, it can be generalized to all women in Ethiopia. Third, multivariate decomposition analysis was applied to understand the source of change in FGM practice. Fourth, the use of GIS and SaTScan statistical tests helped to detect similar and statistically significant hotspot areas of FGM practice across the surveys and to design effective public health programs.

Limitation, variables were not consistently collected in all EDHS surveys like FGM were not collected in EDHS 2011 and wealth index in EDHS 2000 and this variable was not used for the decomposition analysis. The other limitation was, the SaTScan detect only circular clusters, and irregularly shaped clusters were not detected. Furthermore, the EDHS survey did not incorporate community-level variables like community norm, culture, and beliefs rather it relied on mothers or caregivers report and might have the possibility of social desirability and recall bias since FGM is not socially acceptable though CSA claim that strong effort was made to minimize it mainly through extensive training of data collectors, recruiting experienced data collectors and supervisors this might underestimate our finding.

\section{Conclusions}

Female genital mutilations among women aged 15-49 years have shown a dramatic decrease in FGM over the last 16 years in Ethiopia. About $95 \%$ of the overall change in FGM practice among reproductiveage women over the last 16 years was due to the differences in the effect of characteristics (coefficient) between the 2000 and 2016 EDHS. Mainly the decrease in FGM practice over the study period was attributed to the change in effects of residence, religion, region, media exposure, occupational status, and women education. But, the change in FGM practice due to the difference in endowment or composition between the surveys was not significant.

This study identified significant spatial clusters of FGM practice in Somali, Afar, Harari and border areas of Somali as significant hotspot areas consistently over the three surveys. These results provide further insight into identifying the reason why FGM practice highly concentrated in these regions consistently over the three surveys and dig the deeply rooted factors about the continued experience of FGM practice. Besides, it would help policymakers, programmers and NGOs to design effective public health interventions and enabling efficient and timely spatial targeting to identify significant hotspot areas to achieve the SDGs. 


\section{Abbreviations}

Cl; Confidence Interval, CSA; Central Statistical Agency, DHS; Demographic Health Survey, EA; Enumeration Area, EDHS; Ethiopian Demographic Health Survey, FGM; Female Genital Mutilation, GDP; Gross Domestic Product, GIS; Geographic Information System, LLR; log-likelihood Ratio, LR; Likelihood Ratio, PHC; Population and Housing census, SNNPRs; Southern Nations and Nationality People Regional state, WHO; World Health Organization

\section{Declarations}

Ethical approval and consent to participate

The study was based on secondary analysis of existing survey data with all identifying information removed. Permission for data access was obtained from measure demographic and health survey through an online request from http://www.measuredhsprogram.com. Prior to the actual interview, each woman was asked if she agreed to participate in the study. The GIS data were obtained through explaining the purpose of using GPS data and approval from Measure DHS. Informed consent was obtained from the participants, their guardian or household heads

Consent for publication

Not applicable since the study was a secondary data analysis already collected by CSA

Availability of data and materials

Data is available online and you can access it from www.measuredhs.com.

Competing Interests

Authors declare that they have no conflict of interest

Funding

No funding was obtained for this study.

Authors contribution

$\mathrm{GA}, \mathrm{CD}, \mathrm{AB}, \mathrm{AZ}, \mathrm{AM}, \mathrm{YY}$ and $\mathrm{SA}$ conceived the study. $\mathrm{GA}$ analyzed the data. $\mathrm{GA}, \mathrm{CD}, \mathrm{AB}, \mathrm{AZ}, \mathrm{AM}, \mathrm{YY}$ and SA drafted the manuscript and reviewed the article. $G A, C D, A B, A Z, A M, Y Y$ and $S A$ extensively reviewed the article. All authors read and approved the final manuscript.

Acknowledgments

We greatly acknowledge MEASURE DHS for granting access to 2016 Ethiopia Demographic and Health Survey data. 


\section{References}

1. Rahman A, Toubia N. Female genital mutilation: A practical guide to worldwide laws \& policies: Zed Books; 2000.

2. Toubia N. Female circumcision as a public health issue. New England Journal of Medicine. 1994;331(11):712-6.

3. UNICEF. Female genital mutilation/cutting: a global concern. 2016 [http://www. unicef. org/media/files/FGMC_2016_brochure_final_UNICEF_SPREAD. pdf]. Accessed; 2016.

4. Fund UNCs, Gupta GR. Female Genital Mutilation/Cutting: A statistical overview and exploration of the dynamics of change. Reproductive Health Matters. 2013:184-90.

5. Toubia NF, Sharief E. Female genital mutilation: have we made progress? International Journal of Gynecology \& Obstetrics. 2003;82(3):251-61.

6. Muteshi JK, Miller S, Belizán JM. The ongoing violence against women: female genital mutilation/cutting. Reproductive health. 2016;13(1):44.

7. Kandala N-B, Ezejimofor MC, Uthman OA, Komba P. Secular trends in the prevalence of female genital mutilation/cutting among girls: a systematic analysis. BMJ global health. 2018;3(5):e000549.

8. Organization WH. An update on WHO's work on female genital mutilation (FGM): Progress report. Geneva: World Health Organization, 2011.

9. Johnsdotter S. The FGM legislation implemented: Experiences from Sweden. Malmo University. 2009:1-12.

10. Finke E. Genital mutilation as an expression of power structures: ending FGM through education, empowerment of women and removal of taboos. African journal of reproductive health. 2006;10(2):13-7.

11. Macro. CSAEaO. Ethiopia Demographic and Health Survey 2000. Addis Ababa, Ethiopia and Calverton, Maryland, USA:: Central Statistical Authority and ORC Macro., 2001 2001. Report No.

12. Macro. CSAEaO. Ethiopia Demographic and Health Survey 2005. Addis Ababa, Ethiopia and Calverton, Maryland, USA:: Central Statistical Agency and ORC Macro., 2006.

13. ICF CSACEa. Ethiopia Demographic and Health Survey 2016. Addis Ababa, Ethiopia, and Rockville, Maryland, USA: CSA and ICF., 2016.

14. Gebremicheal K, Alemseged F, Ewunetu H, Tolossa D, Ma'alin A, Yewondwessen M, et al. Sequela of female genital mutilation on birth outcomes in Jijiga town, Ethiopian Somali region: a prospective cohort study. BMC pregnancy and childbirth. 2018;18(1):305.

15. Ethiopia U. Girls Empowerment Race in Samara to end Female Genital Mutilation/Cutting. UNFPA,unicef: 2015.

16. Reisel D, Creighton SM. Long term health consequences of Female Genital Mutilation (FGM). Maturitas. 2015;80(1):48-51. 
17. Kaplan A, Forbes M, Bonhoure I, Utzet M, Martín M, Manneh M, et al. Female genital mutilation/cutting in The Gambia: long-term health consequences and complications during delivery and for the newborn. International journal of women's health. 2013;5:323.

18. Missailidis K, Gebre-Medhin M. Female genital mutilation in eastern Ethiopia. The Lancet. 2000;356(9224):137-8.

19. Masho SW, Matthews L. Factors determining whether Ethiopian women support continuation of female genital mutilation. International Journal of Gynecology \& Obstetrics. 2009;107(3):232-5.

20. Yirga WS, Kassa NA, Gebremichael MW, Aro AR. Female genital mutilation: prevalence, perceptions and effect on women's health in Kersa district of Ethiopia. International journal of women's health. $2012 ; 4: 45$.

21. Setegn T, Lakew Y, Deribe K. Geographic variation and factors associated with female genital mutilation among reproductive age women in Ethiopia: a national population based survey. PloS one. 2016;11(1):e0145329.

22. Mitike G, Deressa W. Prevalence and associated factors of female genital mutilation among Somali refugees in eastern Ethiopia: a cross-sectional study. BMC public health. 2009;9(1):264.

23. Gebremariam K, Assefa D, Weldegebreal F. Prevalence and associated factors of female genital cutting among young adult females in Jigjiga district, eastern Ethiopia: a cross-sectional mixed study. International journal of women's health. 2016;8:357.

24. Belda S, Tololu A. Knowledge, attitude and practice of mothers towards female genital mutilation in south west Shoa zone, Oromia region, Ethiopia. MOJ Public Health. 2017;6(2):279-86.

25. Central statistical agency(CSA) I. Ethiopian Demographic and Health survey. Addis Abeba: Addis Ababa, Ethiopia, and Rockville, Maryland, USA: CSA and ICF, 2016.

26. Adugna A. Health Institutions and Services. Addis Abeba: July 2014.

27. 2016. CSACEal. Ethiopia Demographic and Health Survey 2016. Addis Ababa, Ethiopia, and Rockville, Maryland, USA: CSA and ICF. 2016.

28. Powers DA, Yoshioka H, Yun M-S. mvdcmp: Multivariate decomposition for nonlinear response models. The Stata Journal. 2011;11(4):556-76.

29. Waldhör T. The spatial autocorrelation coefficient Moran's I under heteroscedasticity. Statistics in Medicine. 1996;15(7-9):887-92.

30. Tsai P-J, Lin M-L, Chu C-M, Perng C-H. Spatial autocorrelation analysis of health care hotspots in Taiwan in 2006. BMC Public Health. 2009;9(1):464.

31. Bhunia GS, Shit PK, Maiti R. Comparison of GIS-based interpolation methods for spatial distribution of soil organic carbon (SOC). Journal of the Saudi Society of Agricultural Sciences. 2018;17(2):11426.

32. Kulldorff M. SaTScanTM user guide. Boston; 2006.

33. Oduro A, Ansah P, Hodgson A, Afful T, Baiden F, Adongo P, et al. Trends in the prevalence of female genital muti-lation and its effect on delivery outcomes in the kassena-nankana district of northern 
Ghana. Ghana medical journal. 2006;40(3).

34. Rahlenbeck S, Mekonnen W, Melkamu Y. Female genital cutting starts to decline among women in Oromia, Ethiopia. Reproductive biomedicine online. 2010;20(7):867-72.

35. Adeokun LA, Oduwole M, Oronsaye F, Gbogboade A, Aliyu N, Adekunle W, et al. Trends in female circumcision between 1933 and 2003 in Osun and Ogun States, Nigeria: a cohort analysis. African journal of reproductive health. 2006;10(2):48-56.

36. Chikhungu LC, Madise NJ. Trends and protective factors of female genital mutilation in Burkina Faso: 1999 to 2010. International journal for Equity in Health. 2015;14(1):42.

37. Marcusán AK, Singla LR, Secka DM, Utzet M, Le Charles M-A. Female genital mutilation/cutting: changes and trends in knowledge, attitudes, and practices among health care professionals in The Gambia. International journal of women's health. 2016;8:103.

38. Edouard E, Olatunbosun O, Edouard L. International efforts on abandoning female genital mutilation. Elsevier; 2013.

39. Andarge MY. The Difficulties of Ending Female Genital Mutilation (FGM): Case of Afar Pastoralist Communities in Ethiopia. Retrieved fromwww ohchr org/Documents/Issues/Women/WRGS/FGM/NGOs/ActionFor. 2014.

40. Van Rossem R, Meekers D, Gage AJ. Trends in attitudes towards female genital mutilation among ever-married Egyptian women, evidence from the Demographic and Health Surveys, 1995-2014: paths of change. International Journal for Equity in Health. 2016;15(1):31.

41. Dalal K, Lawoko S, Jansson B. Women's attitudes towards discontinuation of female genital mutilation in Egypt. Journal of injury and violence research. 2010;2(1):41.

42. Berg RC, Denison E. Interventions to reduce the prevalence of female genital mutilation/cutting in African countries. Campbell systematic reviews. 2012;8(1):1-155.

43. Kandala N-B, Nwakeze N, Kandala SNI. Spatial distribution of female genital mutilation in Nigeria. The American journal of tropical medicine and hygiene. 2009;81(5):784-92.

44. Achia TN. Spatial modelling and mapping of female genital mutilation in Kenya. BMC public health. 2014;14(1):276.

45. Abathun AD, Gele AA, Sundby J. Attitude towards the practice of female genital cutting among school boys and girls in Somali and Harari Regions, eastern Ethiopia. Obstetrics and gynecology international. 2017;2017.

\section{Tables}

Table 1: percentage distribution of characteristics of women in 2000, 2005 and 2016 Ethiopian Demographic and Health Surveys 


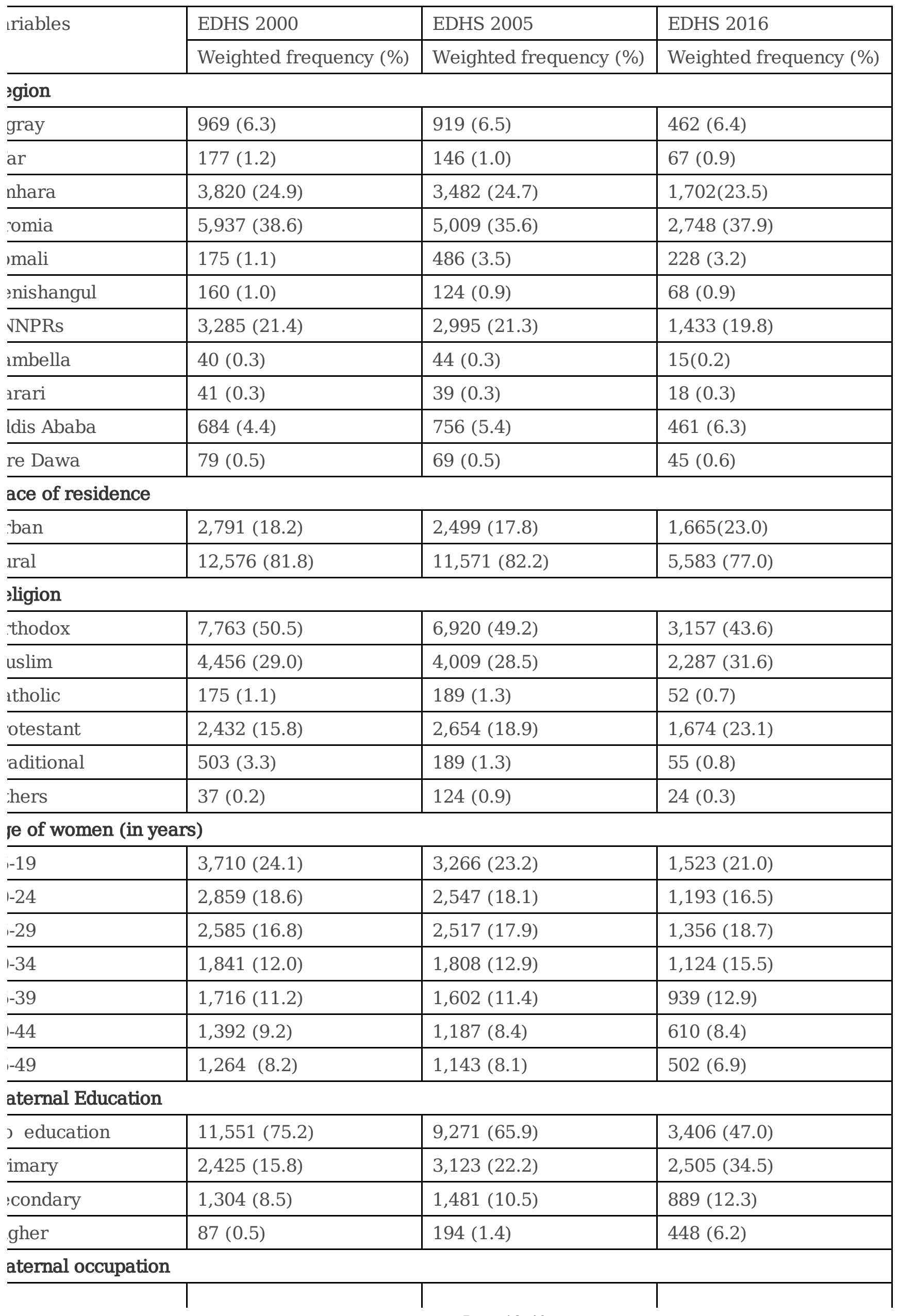




\begin{tabular}{|c|c|c|c|}
\hline tt working & $5,671(36.9)$ & $9,312(66.2)$ & $3,516(48.5)$ \\
\hline 'ofessional & $107(0.7)$ & $181(1.3)$ & $198(2.7)$ \\
\hline erical & $88(0.6)$ & $56(0.4)$ & $71(1.0)$ \\
\hline ıles & 2,038 (13.3) & $1,494(10.6)$ & $1,127(15.6)$ \\
\hline rriculture employee & $5,687(37.0)$ & $2,484(17.7)$ & $1,496(20.6)$ \\
\hline rvices & $197(1.3)$ & $15(0.1)$ & $275(3.8)$ \\
\hline illed manual & $1,472(9.6)$ & $289(2.1)$ & $285(3.9)$ \\
\hline ıskilled manual & $103(0.7)$ & $238(1.7)$ & $280(3.9)$ \\
\hline \multicolumn{4}{|l|}{ edia exposure } \\
\hline : & $5,222(34.0)$ & $6,511(46.3)$ & $3,141(43.3)$ \\
\hline ) & $10,115(66.0)$ & 7,559 (53.7) & $4,107(56.7)$ \\
\hline \multicolumn{4}{|l|}{ ealth status } \\
\hline iorest & & $2,427(17.3)$ & $1,127(15.5)$ \\
\hline Ior & & $2,643(18.8)$ & $1,284(17.7)$ \\
\hline iddle & & $2,732(19.4)$ & $1,408(19.4)$ \\
\hline $\mathrm{ch}$ & & 2,646 (18.8) & $1,445(19.9)$ \\
\hline chest & & $3,621(25.7)$ & $1,984(27.4)$ \\
\hline
\end{tabular}

Table 2. The trend in FGM practice among reproductive age women by selected characteristics, 2000, 2005, and 2016 Ethiopian Demographic and Health Surveys 


\begin{tabular}{|c|c|c|c|c|c|c|}
\hline \multirow[t]{2}{*}{ Characteristics } & \multirow{2}{*}{$\begin{array}{l}\text { EDHS } \\
2000\end{array}$} & \multirow{2}{*}{$\begin{array}{l}\text { EDHS } \\
2005\end{array}$} & \multirow{2}{*}{$\begin{array}{l}\text { EDHS } \\
2016\end{array}$} & \multicolumn{3}{|c|}{ Point difference in prevalence of FGM } \\
\hline & & & & $\begin{array}{lll}\text { Phase } & 1 & \text { (2005- } \\
\text { 2000) } & & \end{array}$ & $\begin{array}{l}\text { Phase } 2 \\
(2016- \\
2005)\end{array}$ & $\begin{array}{l}\text { Phase } 3 \\
(2016- \\
2000)\end{array}$ \\
\hline \multicolumn{7}{|l|}{ Place of residence } \\
\hline Urban & 79.8 & 68.5 & 55.5 & -11.3 & -13.0 & -24.3 \\
\hline Rural & 79.9 & 75.5 & 74.8 & -4.4 & -0.7 & -5.1 \\
\hline \multicolumn{7}{|l|}{ Religion } \\
\hline Orthodox & 76.8 & 67.5 & 58.8 & -9.5 & -8.7 & -18.0 \\
\hline Muslim & 91.8 & 88.9 & 84.9 & -2.9 & -4.0 & -6.9 \\
\hline Catholic & 66.9 & 76.9 & 73.7 & 10.0 & -3.2 & 6.8 \\
\hline Protestant & 71.9 & 71.3 & 73.2 & -0.6 & 1.9 & 2.5 \\
\hline Traditional & 66.8 & 49.2 & 62.1 & -17.6 & 11.9 & -4.7 \\
\hline \multicolumn{7}{|l|}{ Age of women } \\
\hline $15-19$ & 70.7 & 62.2 & 51.6 & -8.5 & -10.6 & -19.1 \\
\hline $20-24$ & 78.3 & 73.0 & 63.3 & -5.3 & -9.7 & -15.0 \\
\hline $25-29$ & 81.4 & 77.6 & 73.4 & -3.8 & -4.2 & -8.0 \\
\hline 30-34 & 86.2 & 78.0 & 82.2 & -8.2 & 4.2 & -4.0 \\
\hline 35-39 & 83.6 & 81.2 & 80.8 & -2.4 & -0.4 & -2.8 \\
\hline $40-44$ & 85.8 & 81.6 & 77.2 & -4.2 & -4.4 & $\begin{array}{l}-8.6 \\
\end{array}$ \\
\hline $45-49$ & 86.8 & 80.8 & 81.5 & -6.0 & 0.7 & -5.3 \\
\hline \multicolumn{7}{|c|}{ Maternal education } \\
\hline No education & 80.4 & 77.3 & 81.0 & -3.1 & 3.7 & 0.6 \\
\hline Primary & 78.4 & 70.8 & 66.3 & -7.6 & -4.5 & -12.1 \\
\hline Secondary & 77.7 & 65.1 & 50.7 & -12.6 & -14.4 & -27.0 \\
\hline Higher & 85.5 & 55.6 & 50.7 & -29.9 & -4.9 & -34.8 \\
\hline \multicolumn{7}{|l|}{ Women occupation } \\
\hline Not working & 79.6 & 74.2 & 72.9 & -5.4 & -1.3 & -6.7 \\
\hline Professional & 85.5 & 65.2 & 61.9 & -20.3 & -3.3 & -23.6 \\
\hline Clerical & 73.5 & 65.8 & 44.8 & -7.7 & -21.0 & -28.7 \\
\hline Sales & 83.8 & 74.6 & 69.6 & -9.2 & -5.0 & -14.2 \\
\hline $\begin{array}{l}\text { Agricultural } \\
\text { employee }\end{array}$ & 77.6 & 78.0 & 70.5 & 0.4 & -7.5 & -7.1 \\
\hline Services & 86.2 & 67.5 & 72.2 & -18.7 & 4.7 & -14.0 \\
\hline Skilled manual & 83.9 & 68.1 & 63.0 & -15.8 & -5.1 & -20.9 \\
\hline Unskilled manual & 80.6 & 55.9 & 58.2 & -24.7 & 2.3 & -22.4 \\
\hline \multicolumn{7}{|l|}{ Media exposure } \\
\hline Yes & 80.5 & 72.8 & 62.9 & -7.7 & -9.9 & -17.6 \\
\hline
\end{tabular}




\begin{tabular}{|c|c|c|c|c|c|c|}
\hline No & 79.7 & 75.5 & 76.5 & -4.2 & 1.0 & -3.2 \\
\hline \multicolumn{7}{|c|}{ Wealth status } \\
\hline Poorest & & 73.0 & 75.6 & 2.6 & & \\
\hline Poor & & 75.9 & 73.2 & -2.7 & & \\
\hline Middle & & 75.4 & 77.1 & 1.7 & & \\
\hline Rich & & 77.6 & 73.6 & -4.0 & & \\
\hline Richest & & 70.6 & 58.5 & -12.1 & & \\
\hline Total & 79.9 & 74.3 & 70.4 & -5.6 & -3.9 & -9.5 \\
\hline
\end{tabular}

Table 3. The overall decomposition analysis of change in FGM practice in Ethiopia, 2000 to 2016

\begin{tabular}{l|l|l|l|}
\hline genital mutilation & Coef. & {$[95 \%$ conf.Interval $]$} & Pct. \\
\hline & -0.0053 & {$[-0.014,0.0037]$} & 5.1 \\
\hline & -0.099 & {$[-0.114,-0.084]^{* *}$} & 94.9 \\
\hline & -0.104 & {$[-0.115,-0.093]$} & \\
\hline
\end{tabular}

Table 4. The detailed decomposition analysis of the change in FGM practice in Ethiopia, 2000 to 2016 


\begin{tabular}{|c|c|c|c|c|c|}
\hline \multirow{2}{*}{\multicolumn{2}{|c|}{ Genital Mutilation }} & \multicolumn{2}{|c|}{$\begin{array}{l}\text { Difference due to characteristics } \\
\text { (E) }\end{array}$} & \multicolumn{2}{|c|}{ Difference due to coefficient (C) } \\
\hline & & Coef. & Pct. & Coef. & Pct. \\
\hline \multirow[t]{2}{*}{ nce } & Rural & 0 & & 0 & \\
\hline & Urban & $0.003(-0.006,0.011)$ & -2.7 & $0.02[0.01,0.03]^{* *}$ & -20.6 \\
\hline \multirow[t]{11}{*}{ t } & Somali & 0 & & 0 & \\
\hline & Afar & $0.003[-0.006,0.012]$ & -2.8 & $-0.0006[-0.01,0.009]$ & 0.6 \\
\hline & Amhara & $-0.005[-0.02,0.01]$ & 4.9 & $0.013[-0.005,0.03]$ & -12.0 \\
\hline & Oromia & $-0.015[-0.06,-0.029]$ & 14.1 & $0.006[-0.02,0.03]$ & -0.5 \\
\hline & Tigray & $0.013[-0.025,0.05]$ & -12.2 & $0.01[0.0008,0.02]^{* *}$ & -12.2 \\
\hline & Ben-Gumuz & $0.0029[-0.0058,0.012]$ & -2.8 & $0.007[-0.002,0.016]$ & -6.5 \\
\hline & SNNPRs & $-0.0046[-0.018,-0.009]$ & 4.4 & $0.01[-0.009,0.029]$ & -9.7 \\
\hline & Gambella & $0.004[-0.009,0.017]$ & -4.1 & $0.007[-0.0008,0.015]$ & -6.9 \\
\hline & Harari & $-0.0004[-0.002,0.0008]$ & 0.37 & $0.003[-0.006,0.011]$ & -2.4 \\
\hline & Addis Ababa & $-0.005[-0.02,0.01]$ & 4.9 & $0.011[-0.007,0.03]$ & -11.2 \\
\hline & Dire Dawa & $0.001[-0.002,0.004]$ & -1.0 & $-0.0013[-0.011,0.009]$ & 1.2 \\
\hline \multirow[t]{7}{*}{1 age (in } & $15-19$ & $-0.0018[-0.007,0.004]$ & 1.7 & $-0.007[-0.015,0.0009]$ & 6.7 \\
\hline & $20-24$ & $-0.0001[-0.00002,0.00001]$ & 0.005 & $-0.002[-0.009,0.004]$ & 2.3 \\
\hline & $25-29$ & $0.0003[-0.0006,0.0012]$ & -0.28 & $-0.002[-0.008,0.0035]$ & 2.4 \\
\hline & $30-34$ & $0.0001[-0.0006,0.001]$ & -0.1 & $0.0007[-0.004,0.005]$ & -0.6 \\
\hline & $35-39$ & 0 & & 0 & \\
\hline & $40-44$ & $-0.0001[-0.0003,0.0002]$ & 0.07 & $-0.001[-0.005,0.002]$ & 1.2 \\
\hline & $45-49$ & $00002[-0.0008,0.0013]$ & -0.2 & $0.0006[-0.003,0.004]$ & -0.5 \\
\hline \multirow[t]{4}{*}{ ional status } & No education & 0 & & 0 & \\
\hline & Primary & $0.0019[-0.007,0.01]$ & -1.8 & $-0.002[-0.006,0.002]$ & 1.8 \\
\hline & Secondary & $0.0005[-0.001,0.002]$ & -0.5 & $-0.001[-0.006,0.003]$ & 1.2 \\
\hline & Higher & $0.008[-0.02,0.033]$ & -7.6 & $\begin{array}{l}-0.0008 \quad[-0.001, \\
-0.00006]^{* *}\end{array}$ & 0.7 \\
\hline \multirow[t]{3}{*}{ ation } & Not working & 0 & & 0 & \\
\hline & $\begin{array}{l}\text { Gov't } \\
\text { employee }\end{array}$ & $-0.0013[-0.0012,0.0009]$ & 0.1 & $-0.0006[-0.001,0.0003]$ & 0.5 \\
\hline & Self employee & $0.0007[-0.003,0.005]$ & 0.7 & $-0.02[-0.03,-0.009]^{* *}$ & 19.7 \\
\hline \multirow[t]{5}{*}{$\mathrm{n}$} & Orthodox & $-0.0018[-0.011,0.007]$ & 1.8 & $-0.06[-0.11,-0.02]^{* *}$ & 61.9 \\
\hline & Muslim & $-0.006[-0.025,0.012]$ & 5.8 & $-0.05[-0.08,-0.01]^{* *}$ & 43.6 \\
\hline & Protestant & $0.0007[-0.0043,0.0056]$ & -0.6 & $-0.003[-0.016,0.01]$ & 3.1 \\
\hline & Traditional & $-0.0038[-0.015,0.0075]$ & 3.6 & $-0.002[-0.006,0.002]$ & 1.5 \\
\hline & Catholic & 0 & & 0 & \\
\hline exposure & Yes & $-0.0006[-0.0025,0.0014]$ & 0.5 & $-0.012[-0.022,-0.003]^{* *}$ & 11.8 \\
\hline
\end{tabular}




\begin{tabular}{l|l|l|l|l|l|} 
& No & 0 & & 0 & \\
\hline $\mathrm{nt}$ & & & & $0.02[-0.15,0.20]$ & -23.4 \\
\hline
\end{tabular}

Table 5. SaTScan analysis result of FGM practice in Ethiopia, 2000 


\begin{tabular}{|c|c|c|c|c|c|c|c|}
\hline ers & $\begin{array}{l}\text { Enumeration areas(EAs)/ } \\
\text { clusters detected }\end{array}$ & Coordinates/radius & Population & Cases & $\mathrm{RR}$ & LLR & P-value \\
\hline L) & $\begin{array}{l}255,256,260,274,257,258, \\
259,251,253,250,273,272, \\
252,249,254,262,248,244, \\
261,275,506,264,263,265, \\
218,246,425,507,424,426, \\
422,423,509,515,421,432, \\
505,427,431,420,438,434, \\
447,514,436,450,435,439, \\
440,448,437,452,441,442, \\
443,449,451,444,453,445, \\
446,429,513,242,433,219, \\
428,430,538,539,537,36, \\
521,510,522,535,523,531, \\
534,528,533,529,530,527, \\
519,532,517,524,526,518, \\
516,511,540,512,508,247, \\
220,224,245,221,223,222, \\
213,57,56,53,52,54,55,1, \\
214,217,81,64,212,215, \\
61,60,75,59,58,62,78,74, \\
77,79,216,76,80,69,82,71, \\
83,66,73,70,72,68,67,65, \\
63\end{array}$ & $\begin{array}{lll}(9.867651 & & \mathrm{N}, \\
43.086403 & \mathrm{E}) \quad / \\
348.25 \mathrm{~km} & \end{array}$ & 3807 & 3704 & 1.35 & 711.9 & $<0.00001$ \\
\hline ) & 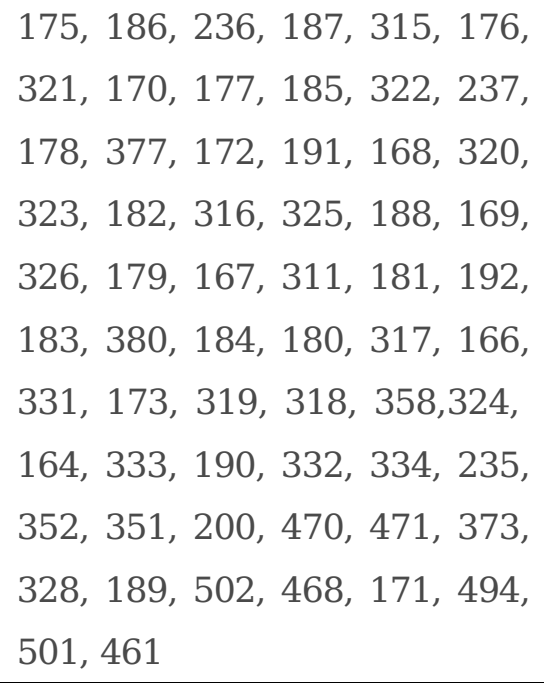 & $\begin{array}{ll}(8.527592 & \mathrm{N}, \\
37.185362 & \mathrm{E}) \quad / \\
177.79 \mathrm{~km} & \end{array}$ & 2034 & 1899 & 1.23 & 192.8 & $<0.00001$ \\
\hline & $\begin{array}{l}129,128,100,130,98,142, \\
131,99,132,101,158,116, \\
117,139,109,96,135,97,36,\end{array}$ & $\begin{array}{llr}(11.086446 & \mathrm{N}, \\
38.158578 & \mathrm{E}) \quad / \\
155.51 \mathrm{~km} & \end{array}$ & 1267 & 1150 & 1.17 & 74.2 & $<0.0001$ \\
\hline
\end{tabular}




\begin{tabular}{|c|c|c|c|c|c|c|c|c|}
\hline & $\begin{array}{l}115,143,138,140,95,105, \\
106,154,133,141,110,144, \\
134,118,93,155,94,37,194, \\
193,120,238,114, \\
119,104,148,111,102,95, \\
147\end{array}$ & & & & & & & \\
\hline & $\begin{array}{l}304,293,305,313,295,306, \\
301,280,282,298,302,292, \\
296,281,297,160,303,299\end{array}$ & $\begin{array}{l}(10.329109 \\
35.159160 \\
75.37 \mathrm{~km}\end{array}$ & $\begin{array}{l}\mathrm{N}, \\
\text { E) } /\end{array}$ & 492 & 477 & 1.25 & 73.7 & $<0.0001$ \\
\hline & $\begin{array}{l}346,347,345,339,228,342, \\
343\end{array}$ & $\begin{array}{l}(6.495022 \\
38.853737 \\
46.64 \mathrm{~km} \\
\end{array}$ & $\begin{array}{l}\mathrm{N}, \\
\text { E) } /\end{array}$ & 187 & 181 & 1.14 & 26.96 & $<0.0001$ \\
\hline & $266,268,276,243,267$ & $\begin{array}{l}(5.134748 \\
40.418175 \\
180.04 \mathrm{~km}\end{array}$ & $\begin{array}{l}\mathrm{N}, \\
\text { E) } /\end{array}$ & 26 & 25 & 1.27 & 26.27 & $<0.0001$ \\
\hline & $361,362,364,363,357,353$ & $\begin{array}{l}(6.520039 \\
37.390891 \\
57.41 \mathrm{~km}\end{array}$ & E) $\quad /$ & 166 & 154 & 1.19 & 12.9 & 0.0017 \\
\hline & $234,270,233,271$ & $\begin{array}{l}(3.992650 \\
38.343911 \\
112.67 \mathrm{~km} \\
\end{array}$ & $\begin{array}{l}\mathrm{N}, \\
\text { E) } /\end{array}$ & 92 & 88 & 1.22 & 11.1 & 0.013 \\
\hline & $413,419,412$ & $\begin{array}{l}(7.215608 \\
35.321323 \\
5.17 \mathrm{~km}\end{array}$ & $\begin{array}{l}\mathrm{N}, \\
\text { E) } /\end{array}$ & 61 & 60 & 1.26 & 11.06 & 0.014 \\
\hline 1) & $\begin{array}{l}38,39,40,48,42,43,36,41, \\
37,146,145\end{array}$ & $\begin{array}{l}(12.823525 \\
39.374479 \\
64.31 \mathrm{~km}\end{array}$ & E) $\quad /$ & 256 & 229 & 1.14 & 11.02 & 0.014 \\
\hline
\end{tabular}

Table 6. SaTScan analysis result of FGM practice in Ethiopia, 2005 


\begin{tabular}{|c|c|c|c|c|c|c|}
\hline $\begin{array}{l}\text { Enumeration areas(EAs)/ } \\
\text { Clusters detected }\end{array}$ & Coordinates/radius & Population & Cases & $\mathrm{RR}$ & LLR & P-value \\
\hline 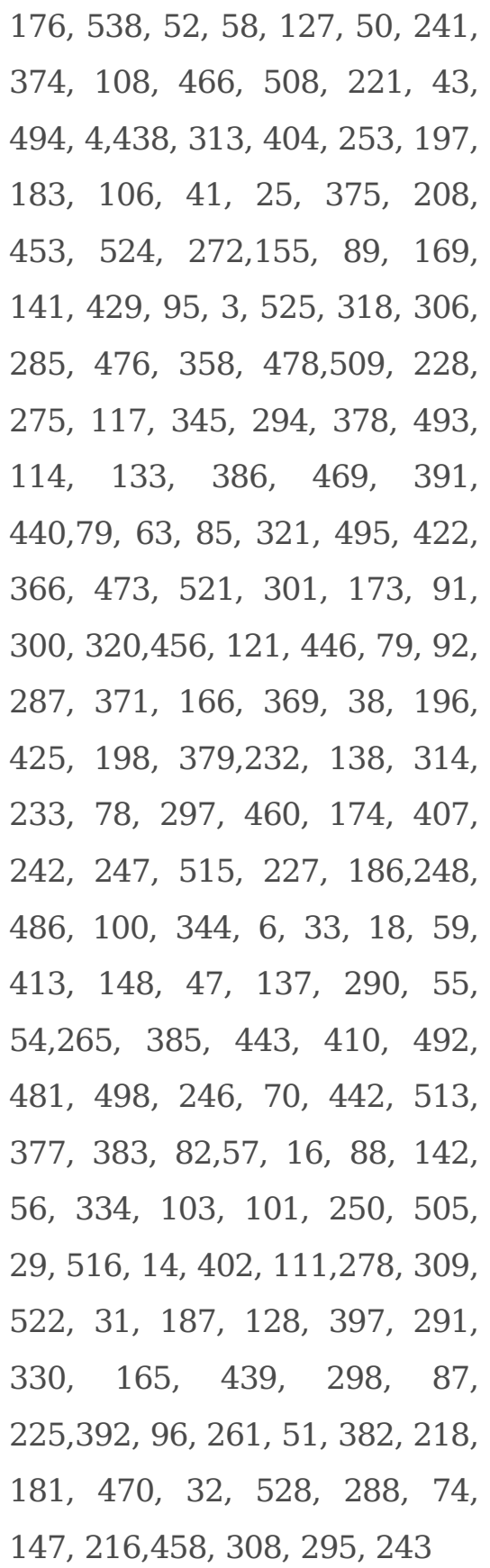 & $\begin{array}{lll}(9.774395 & & \text { N, } \\
43.208576 & \text { E) } \quad / \\
484.13 \mathrm{~km} & & \end{array}$ & 4252 & 3826 & 1.42 & 576.4 & $<0.00001$ \\
\hline 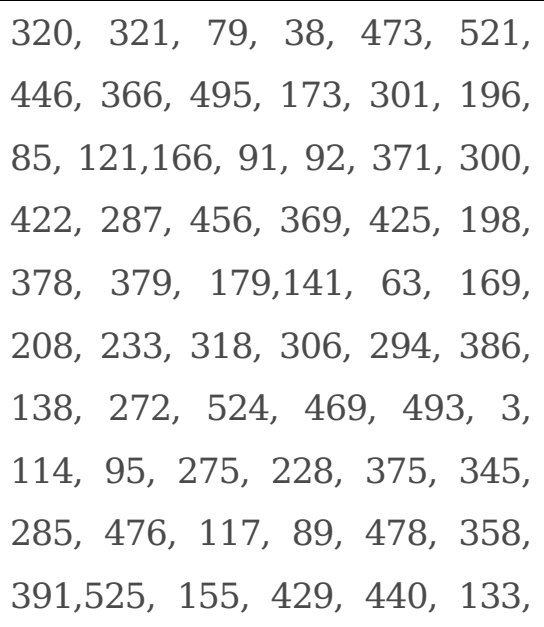 & $\begin{array}{llr}(9.687251 & \mathrm{N}, \\
41.857767 & \mathrm{E}) \quad / \\
206.04 \mathrm{~km} & \end{array}$ & 2782 & 2544 & 1.37 & 400.8 & $<0.0001$ \\
\hline
\end{tabular}




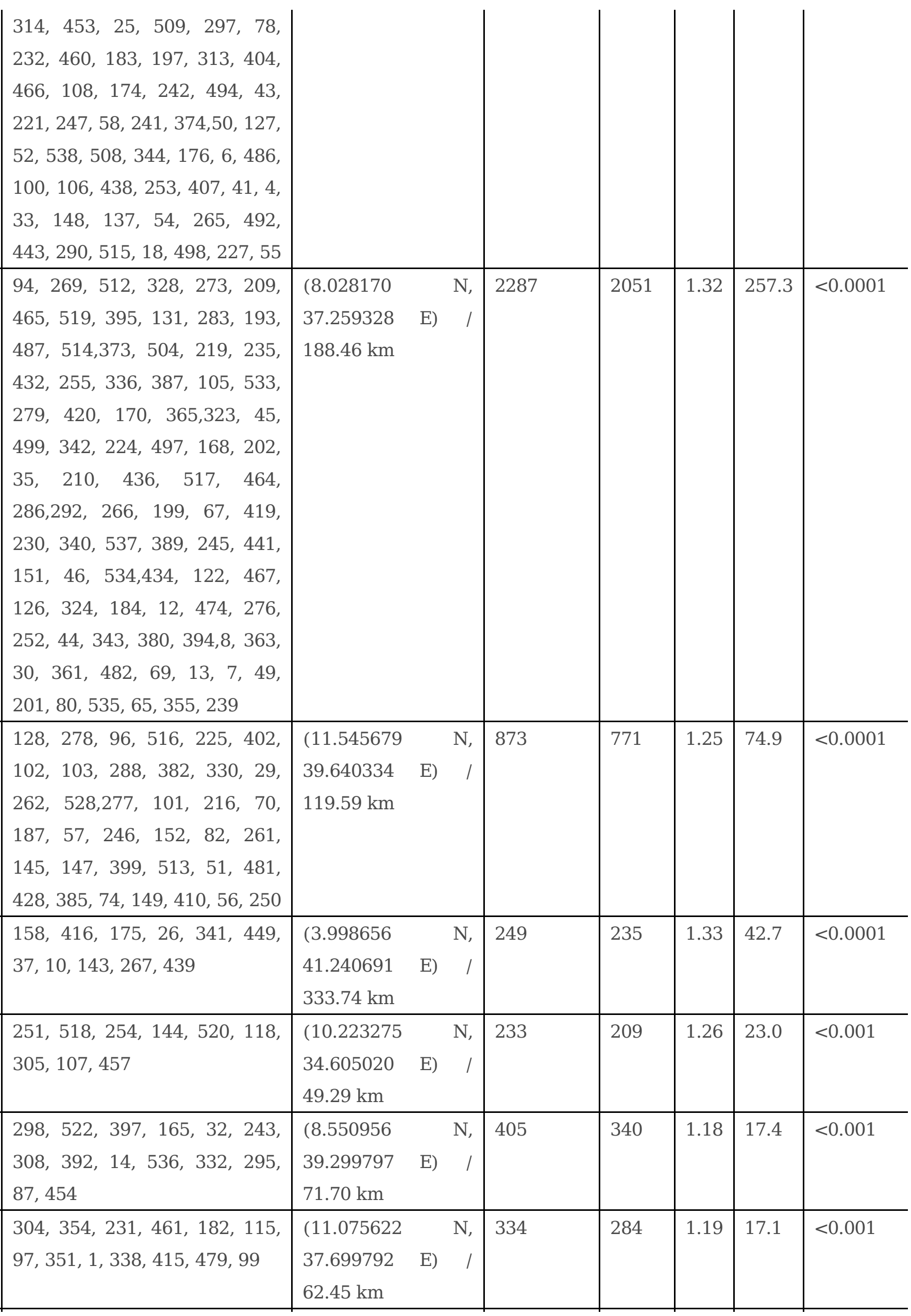




\begin{tabular}{|c|c|c|c|c|c|c|}
\hline $145,277,262,428$ & $\begin{array}{llr}(12.172298 & & \mathrm{N}, \\
39.074809 & \mathrm{E}) & / \\
49.37 \mathrm{~km} & & \end{array}$ & 88 & 81 & 1.29 & 11.5 & 0.006 \\
\hline 502 & $\begin{array}{l}(13.163256 \\
39.926912 \text { E) / } 0 \\
\mathrm{~km}\end{array}$ & 30 & 30 & 1.40 & 10.0 & 0.02 \\
\hline
\end{tabular}

Table 7: SaTScan analysis result of FGM practice in Ethiopia, 2016 


\begin{tabular}{|c|c|c|c|c|c|c|}
\hline $\begin{array}{l}\text { Enumeration areas(EAs)/ } \\
\text { Clusters detected }\end{array}$ & Coordinates/radius & Population & Cases & $\mathrm{RR}$ & LLR & P-value \\
\hline 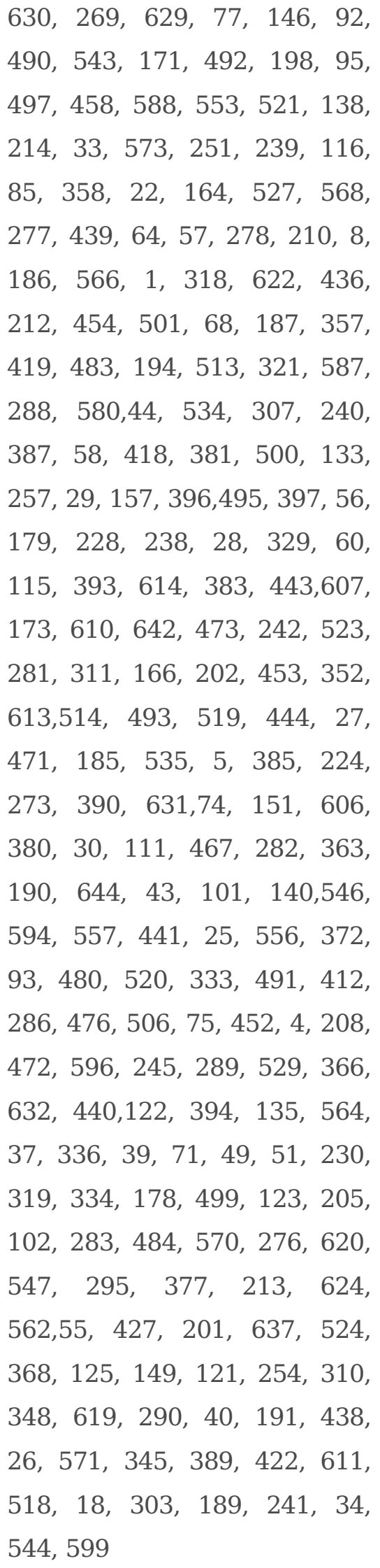 & $\begin{array}{lll}(7.717178 & & \mathrm{N}, \\
46.991580 & \mathrm{E}) & / \\
900.49 \mathrm{~km} & & \end{array}$ & 2384 & 2033 & 1.42 & 243.6 & $<0.00001$ \\
\hline $\begin{array}{l}33,527,277,568,116,22, \\
239,573,251,214,439,64\end{array}$ & $\begin{array}{lll}(9.191989 & & \mathrm{N}, \\
43.573399 & \mathrm{E}) & /\end{array}$ & 2043 & 1750 & 1.39 & 210.4 & $<0.00001$ \\
\hline
\end{tabular}


$57,210,8,458,553,588,521$, $456.66 \mathrm{~km}$ 186, 566, 1, 622, 436, 212, $497,501,307,454,68,357$, 419, 288, 321, 194, 483, 381, $587,44,534,495,387$, 240,580, 513, 58, 396, 418, 257, 157, 500, 329, 29, 397, 133, 56, 238, 228, 60, 179, 28, 393, 614, 383, 115, 443, 610, 173, 607, 642, 473,242, 523, 281, 95, 311, 166, 202, 352, 613, 514, 493, 27, 444, 185, 519, 471, 224, 385, 5, 535, 390, 273, 606, 631, 74, 151, 380, 111, 467, 363, 30, 282, 198, 190, 453, 644, 101, 140, 43, 546, 594, 171, 557, 25, 441, 93, 372, 543, 490, 491, 333, 92, 492, 412, 506, 476, 75, 278, 318, 596, 4, 187, 135, $37,440,632,336,39,85,564$, 358, 245, 629, 122, 529, 164, 51, 230, 49, 71, 146, 334, 283, 102, 366, 286, 499, 178, 276, 484, 570, 452, 620, 205, 547, 138, 77, 630, 480,295, 269, 472, 319, 55, 624, 123, 637, 201, 368, 289, 427, 254

272, 223, 331, 537, 297, 41, 577, 271, 360, 502, 388, 420, 373, 359,174, 142, 14, 565, $152.62 \mathrm{~km}$ 609, 633, 126, 204, 162, 262, $113,347,227,53,578,54,148$, 308, 391, 20, 447, 522, 306, 216, 139, 486, 408, 180, 589, $12,141,215,217,365,432$, 434, 634, 438, 576, 23, 118, $619,26,313,76,468,445,485$, 406,62

502, 577, 331, 142, 272, 227, $(7.701180$ (7.631441 37.861459 . 


\begin{tabular}{|c|c|c|c|c|c|c|c|}
\hline 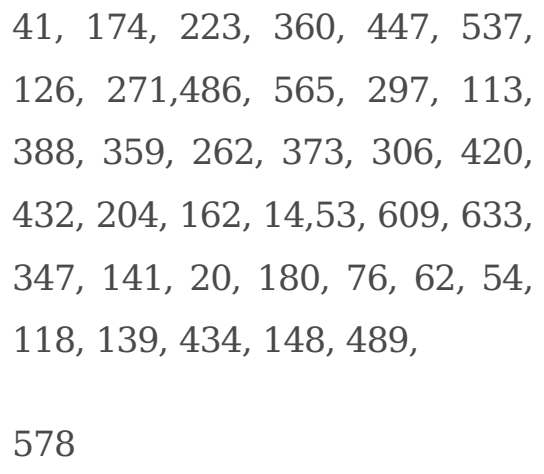 & $\begin{array}{l}37.486551 \\
128.59 \mathrm{~km}\end{array}$ & E) $/$ & & & & & \\
\hline 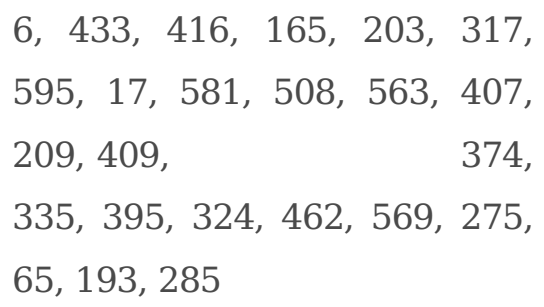 & $\begin{array}{l}(9.942940 \\
34.629272 \\
67.68 \mathrm{~km}\end{array}$ & $\begin{array}{l}\mathrm{N}, \\
\text { E) } /\end{array}$ & 239 & 209 & 1.28 & 23.5 & $<0.0001$ \\
\hline $235,585,127,362$ & $\begin{array}{l}(13.750028 \\
39.991260 \\
16.33 \mathrm{~km}\end{array}$ & $\begin{array}{l}\mathrm{N}, \\
\text { E) } /\end{array}$ & 56 & 55 & 1.43 & 16.8 & $<0.001$ \\
\hline 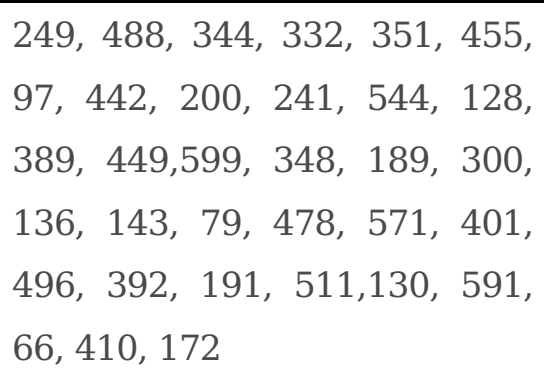 & $\begin{array}{l}(12.335896 \\
39.851758 \\
103.48 \mathrm{~km}\end{array}$ & $\begin{array}{l}\mathrm{N}, \\
\text { E) } /\end{array}$ & 345 & 283 & 1.20 & 16.3 & $<0.001$ \\
\hline $\begin{array}{l}313,468,576,405,634,445, \\
215\end{array}$ & $\begin{array}{l}(6.620913 \\
38.626887 \\
38.40 \mathrm{~km}\end{array}$ & $\begin{array}{l}\text { N, } \\
\text { E) } /\end{array}$ & 89 & 83 & 1.36 & 16.2 & $<0.001$ \\
\hline $130,511,172$ & $\begin{array}{l}(13.169308 \\
39.987117 \\
10.69 \mathrm{~km}\end{array}$ & $\begin{array}{l}\text { N, } \\
\text { E) } /\end{array}$ & 39 & 39 & 1.46 & 14.6 & $<0.01$ \\
\hline
\end{tabular}

Figures 


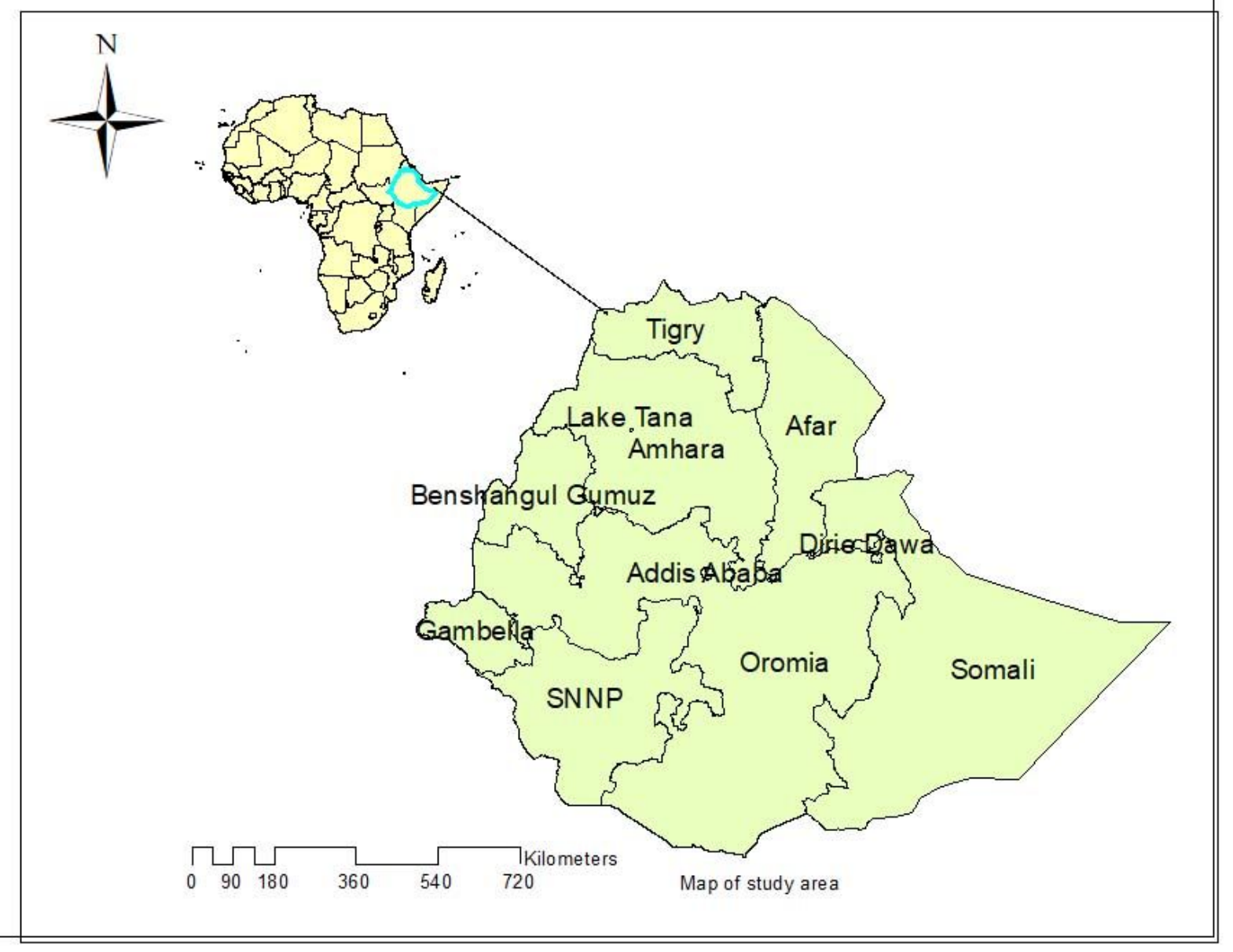

\section{Figure 1}

Trends of FGM practice among reproductive age women in Ethiopia, based on EDHS 2000, 2005 and 2016 


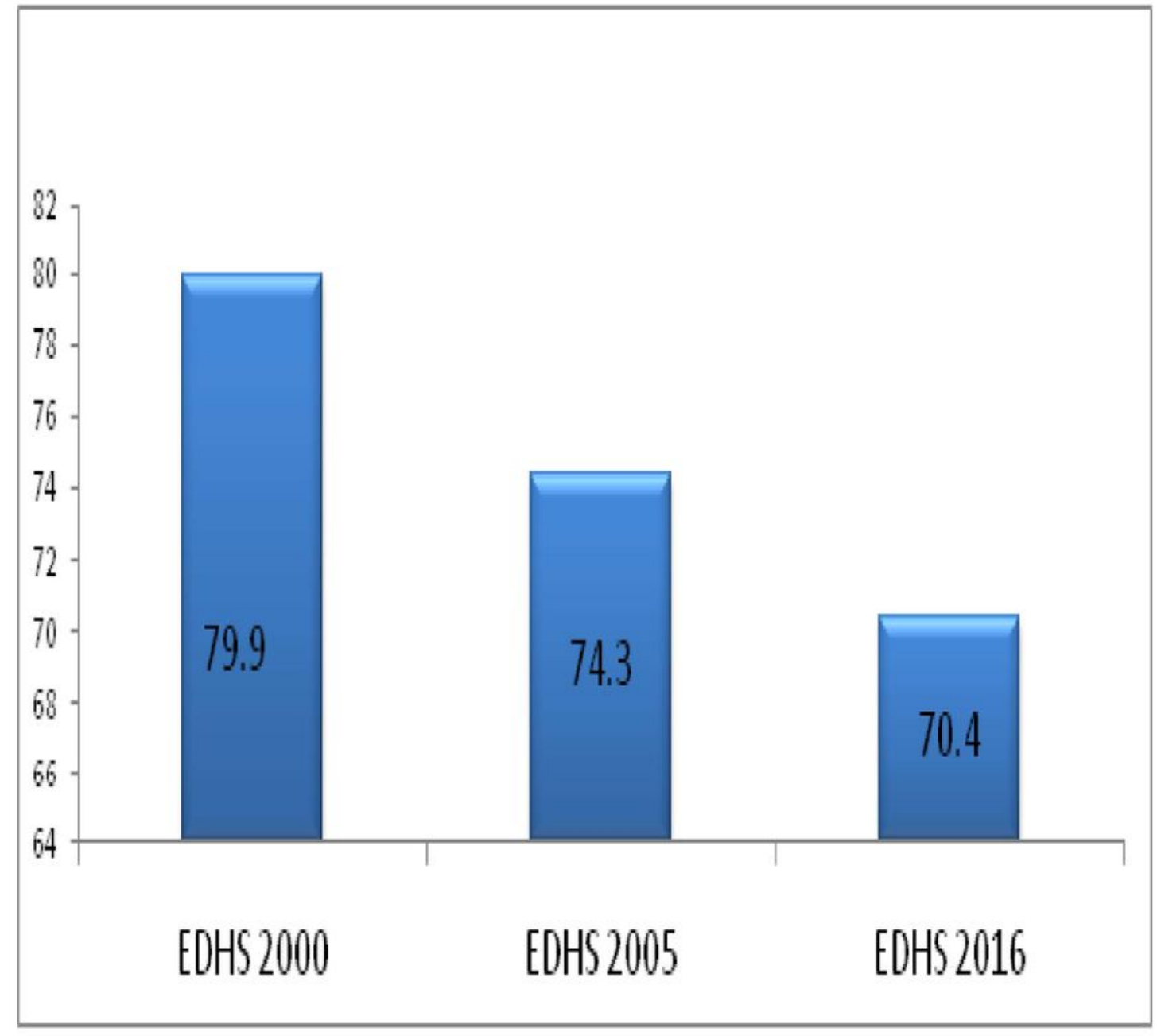

Figure 2

Trends of FGM practice among reproductive age women across regions in Ethiopia, based on EDHS 2000, 2005 and 2016 


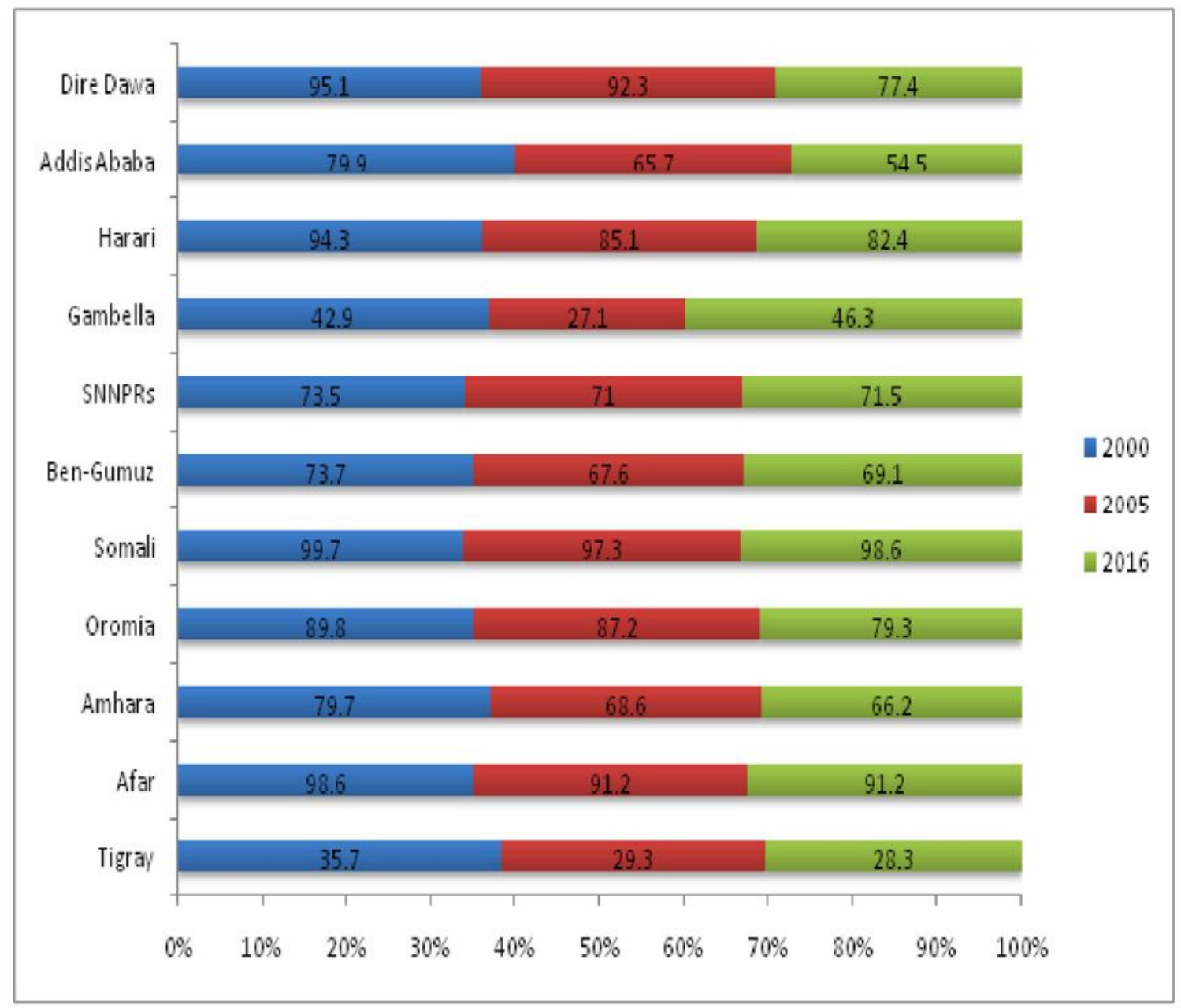

Figure 3

Map of the study area (Source; Shape file from CSA, 2013) 


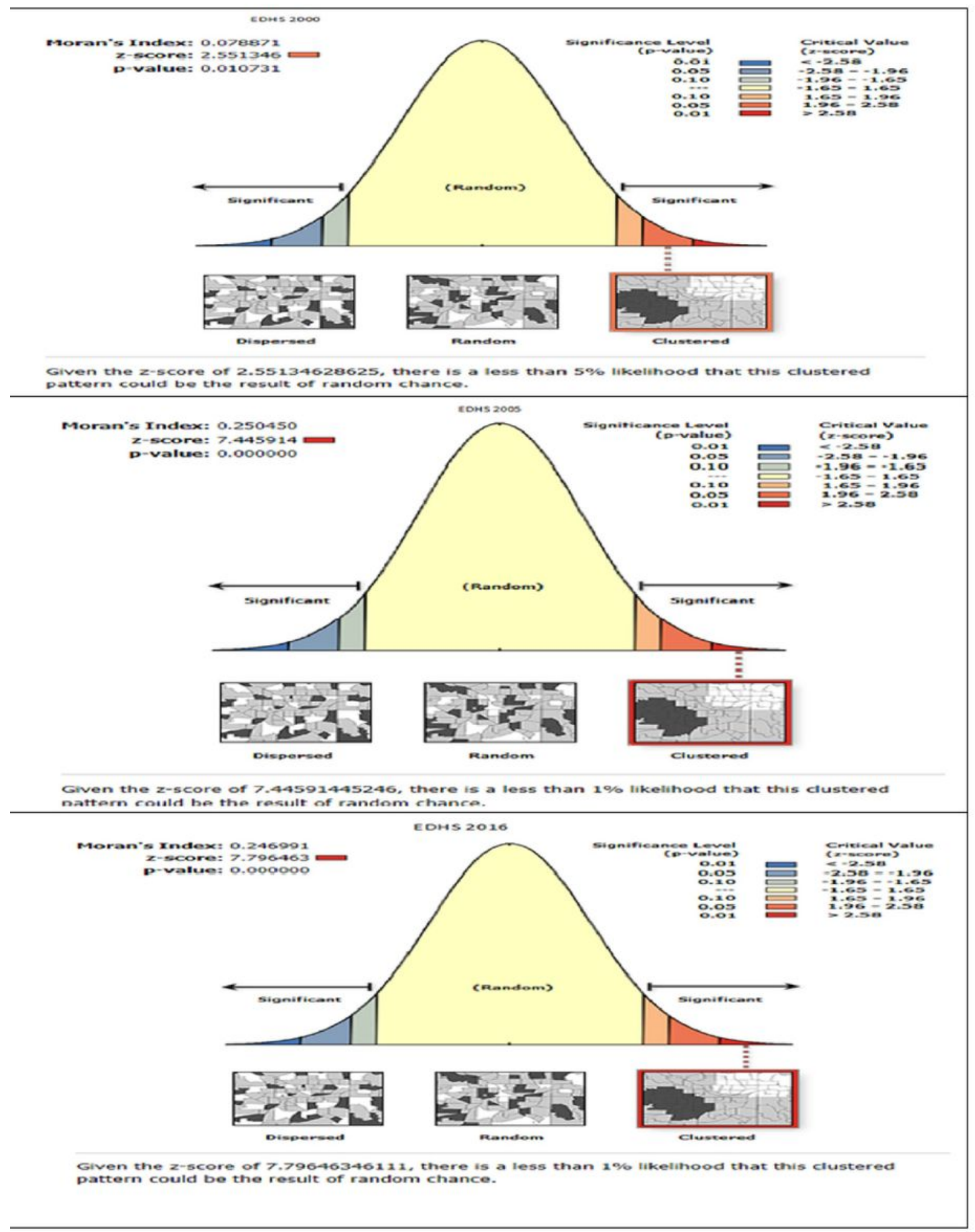

\section{Figure 4}

Global spatial autocorrelation of FGM practice across the surveys (Source; Shape file from CSA, 2013) 


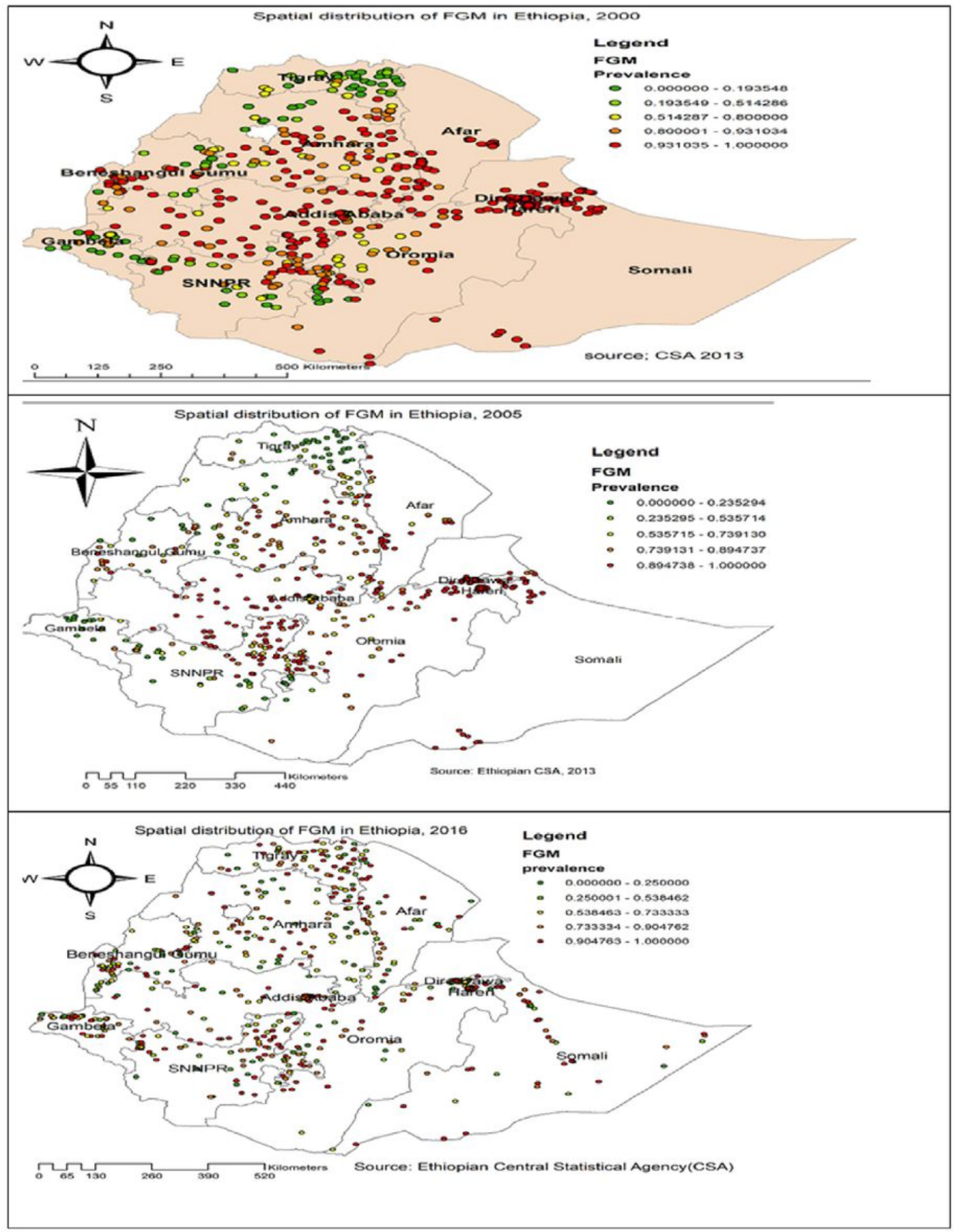

\section{Figure 5}

Spatial distribution of prevalence of FGM practice across the surveys (Source; Shape file from CSA, 2013) 

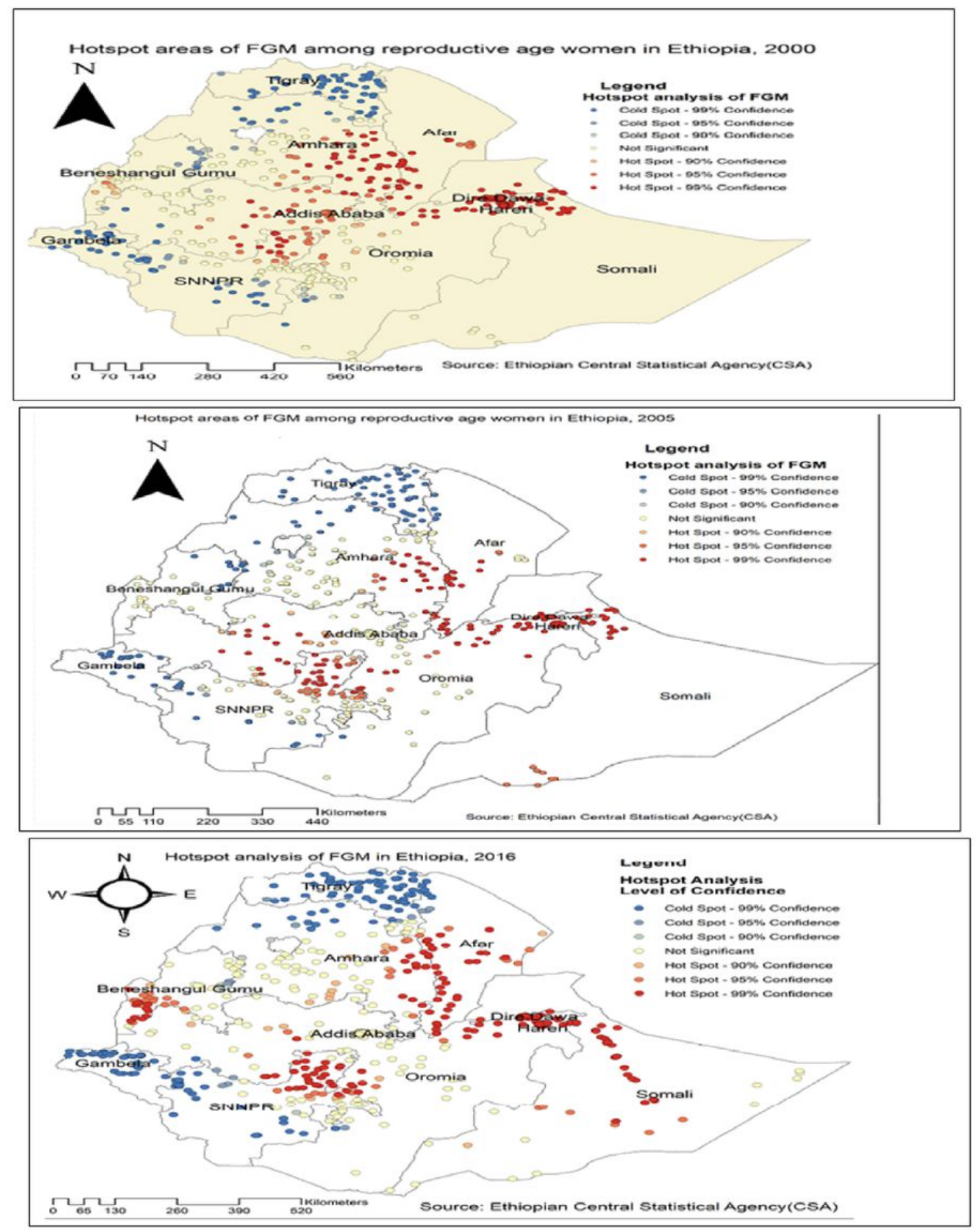

\section{Figure 6}

Hotspot analysis of FGM practice across the surveys (Source; Shape file from CSA, 2013) 

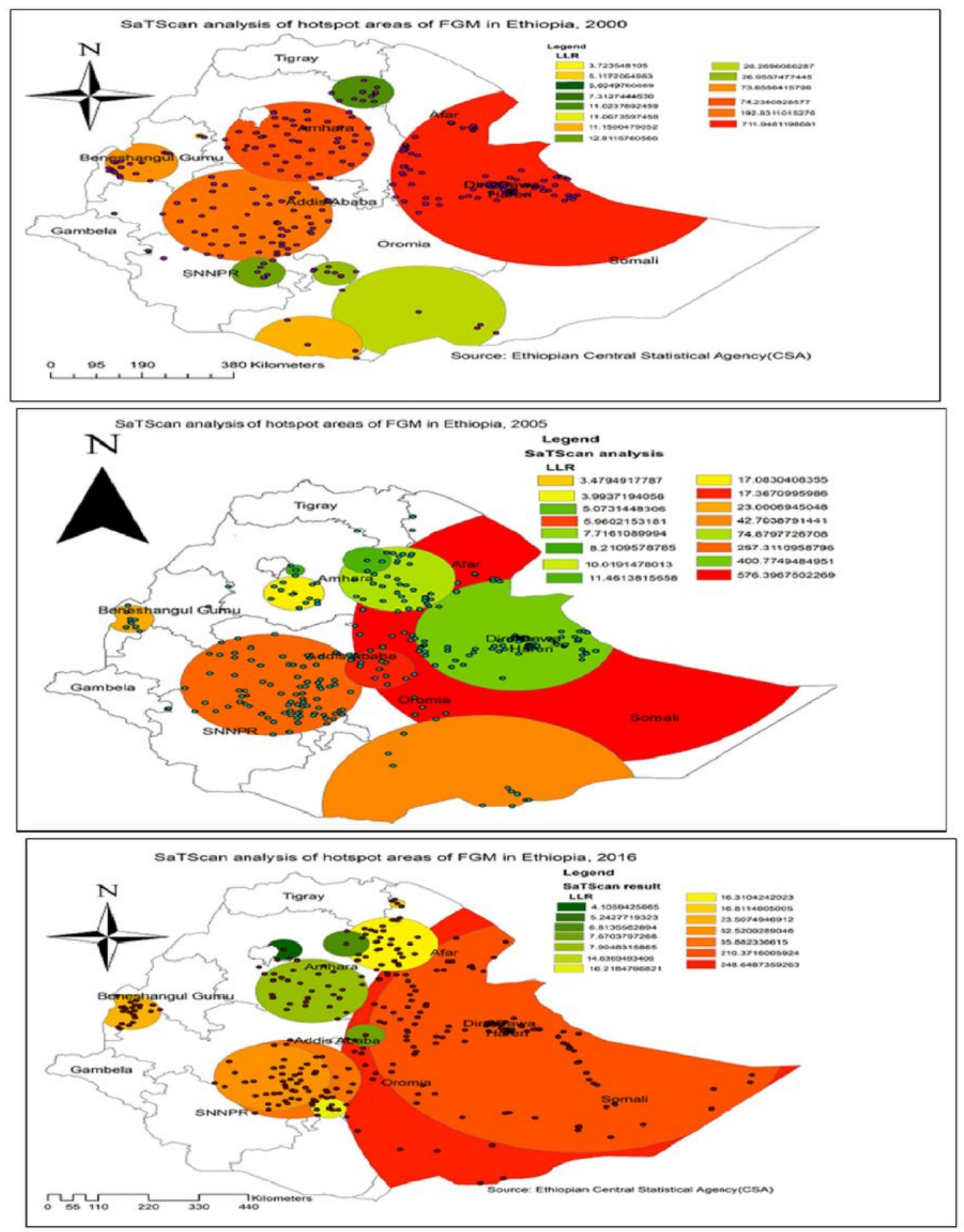

\section{Figure 7}

SaTScan analysis of FGM practice across the surveys (Source; Shape file from CSA, 2013) 

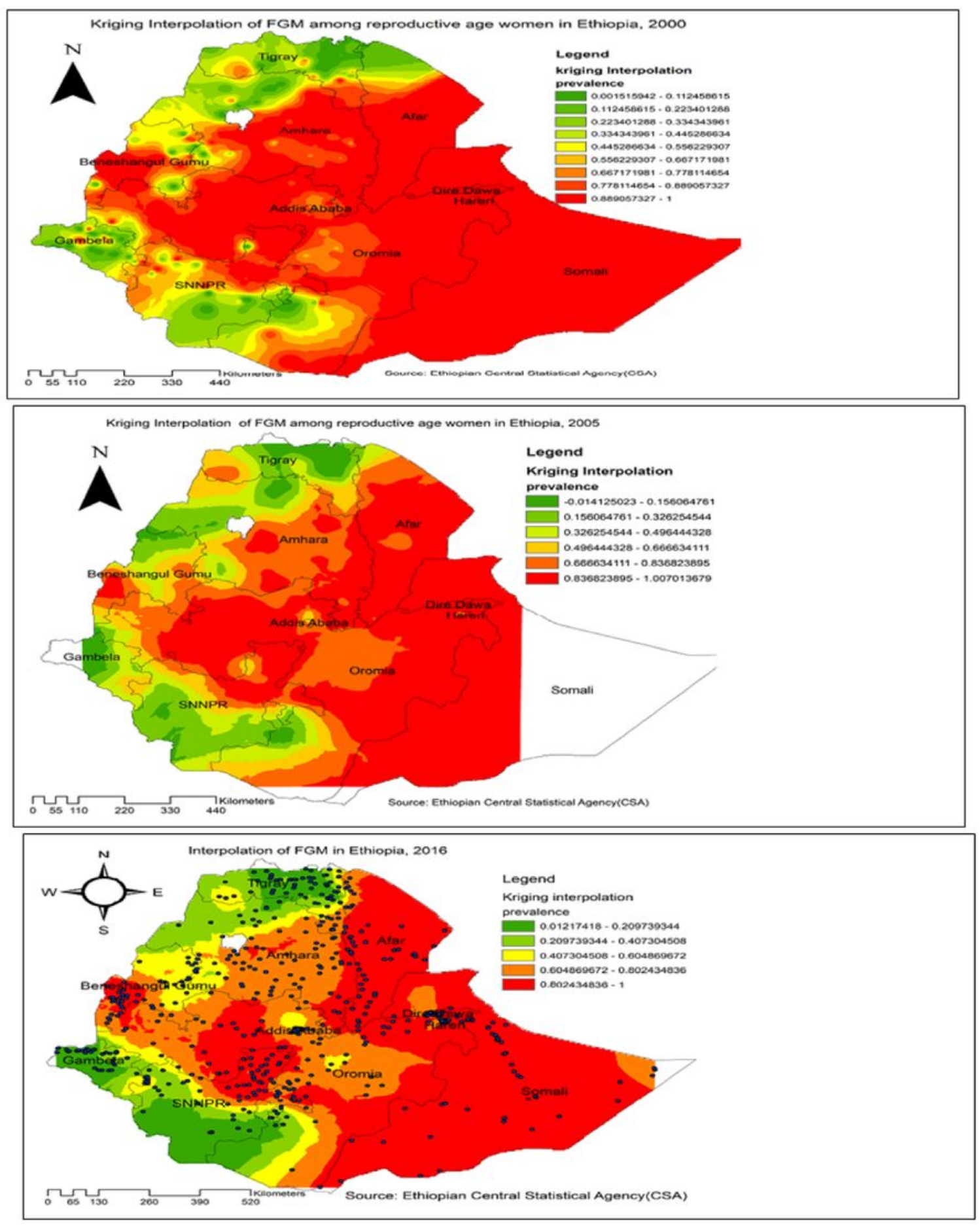

\section{Figure 8}

Interpolation of FGM practice across the surveys (Source; Shape file from CSA, 2013)

\section{Supplementary Files}

This is a list of supplementary files associated with this preprint. Click to download. 
- STROBEchecklist.docx

Page $40 / 40$ 